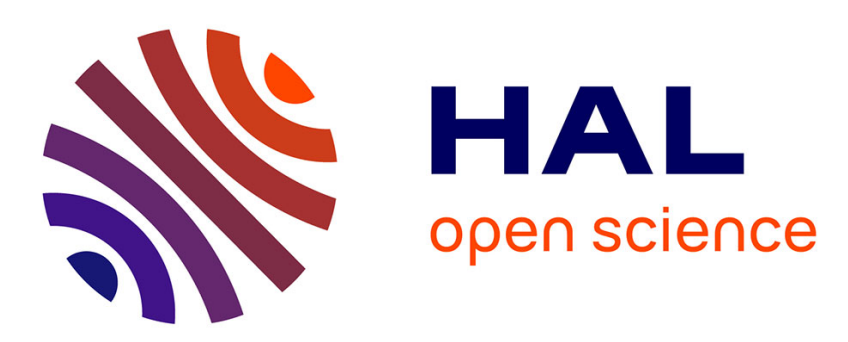

\title{
Hydroamination and Hydroaminoalkylation of Alkenes by Group 3-5 Elements: Recent Developments and Comparison with Late Transition Metals
}

Jérôme Hannedouche, Emmanuelle Schulz

\section{- To cite this version:}

Jérôme Hannedouche, Emmanuelle Schulz. Hydroamination and Hydroaminoalkylation of Alkenes by Group 3-5 Elements: Recent Developments and Comparison with Late Transition Metals. Organometallics, 2018, 37 (23), pp.4313-4326. 10.1021/acs.organomet.8b00431 . hal-02391895

\section{HAL Id: hal-02391895 \\ https://hal.science/hal-02391895}

Submitted on 27 Aug 2021

HAL is a multi-disciplinary open access archive for the deposit and dissemination of scientific research documents, whether they are published or not. The documents may come from teaching and research institutions in France or abroad, or from public or private research centers.
L'archive ouverte pluridisciplinaire HAL, est destinée au dépôt et à la diffusion de documents scientifiques de niveau recherche, publiés ou non, émanant des établissements d'enseignement et de recherche français ou étrangers, des laboratoires publics ou privés. 


\title{
Hydroamination and Hydroaminoalkylation of Alkenes by Group 3- 5 Elements: Recent Developments and Comparison with Late Tran- sition Metals
}

\author{
Jérôme Hannedouche*†t and Emmanuelle Schulz*†† \\ $\dagger$ Institut de Chimie Moléculaire et des Matériaux d’Orsay, UMR 8182, Université Paris-Sud, Rue du Doyen Georges Poitou, \\ Orsay, F-91405, France, + CNRS, Orsay, F-91405, France.
}

\begin{abstract}
This short review highlights recent catalyst developments from Group III to V elements reported in the last few years to promote two highly atom-saving transformations, namely the hydroamination and hydroaminoalkylation, for the synthesis of both cyclic and acyclic nitrogen-containing compounds. A specific emphasis is given to reports leading to scalemic compounds essentially via intramolecular hydroamination catalyzed by Groups III-IV metals and intermolecular hydroaminoalkylation catalyzed by Group V elements. In both transformations, performances of these electropositive metals will be compared with recent developments obtained through late transition metals catalysis.
\end{abstract}

\section{INTRODUCTION}

Hydroamination $^{1}$ and hydroaminoalkylation ${ }^{2}$ reactions are two transformations giving rise to the formation of structurally varied nitrogen-containing cyclic or acyclic compounds, useful as bulk or specialty chemicals. They have known a huge development in the last thirty years. Whereas the first reaction implies the addition of an N-H bond of an amine across a C-C multiple bond, the second is characterized by the addition of the $\alpha-\mathrm{C}-\mathrm{H}$ bond of an alkylamine across $\mathrm{C}-\mathrm{C}$ unsaturation. Numerous elements from the periodic table have been demonstrated active to promote these transformations; this short review lists and comments on recent developments obtained with the use of elements from the Groups III, IV and V. Numerous elements from the periodic table have been demonstrated active to promote these transformations; this short review lists and comments on recent developments obtained with the use of elements from the Groups III, IV and V., highlighting common features between the two historically related reactions in terms of catalyst structures and mechanistic aspects.

Moreover, as non-toxic and readily available species, these elements as catalysts allow direct transformations of unactivated olefins or amine derivatives, and thus perfectly match the concept of green chemistry for atom-economy reactions. Herein will be more specifically developed reports published in the last few years, dealing with the hydroamination or hydroaminoalkylation of unactivated alkene derivatives, and the authors advise to refer to excellent previous reviews on the topics for former articles. ${ }^{1,2}$ A particular emphasis will be placed on complexes that allow enantioselective catalysis, which however does not exist for all elements, until now. This review will be divided according to the reaction type and the Group; however, within a reaction type, a different presenta- tion order will appear essentially to propose a rather historical and mechanistic outlook. Very recent examples for enantioselective hydroamination or hydroaminoalkylation reactions promoted by transition metals will also be introduced for a comparison of the successes and lacks of both types of transformations.

\section{ASYMMETRIC HYDROAMINATION}

\subsection{Introduction}

Since the seminal work of the Marks' group reporting the first asymmetric alkene hydroamination reaction catalyzed by $C_{1}$-symmetric chiral ansa-lanthanocene complexes, intensive research efforts over the last 25 years have been devoted to the development of chiral rare-earth metallocene and nonmetallocene complexes to tackle the challenges associated with this highly atom-economic transformation, namely, the control of both reaction regioselectivity (Markovnikov and anti-Markovnikov) in a highly enantioselective fashion. Although various players of the field have made some significant contributions in this area, ${ }^{1 \mathrm{a}, \mathrm{f}}$ the major breakthrough in terms of reaction rates, enantioselectivity and versatility arose from the group of Hultzsch with the disclosure, in 2006, of the synthesis of rare-earth alkyl complexes $(\mathrm{Ln}=\mathrm{Sc}, \mathrm{Y}, \mathrm{Lu})$ surrounded by $C_{2}$-symmetric chiral 3,3'-bis[tris(aryl)silyl]substituted binaphtholate ligands, such 1 (Scheme 1, left), and their catalytic applications in alkene hydroamination. ${ }^{3 a}$ These complexes are to date amongst the most active and stereoselective rare-earth catalysts for the cyclohydroamination of a variety of aminoalkenes (ee's up to 95 and $61 \%$ for 5- and 6-membered rings respectively). Lately, they have demonstrated their ability to promote the asymmetric Markovnikov intermolecular hydroamination of prima- 
ry aliphatic amines and aliphatic alkenes with high enantioselectivity (51-61\% ee) as the unique example of rareearth-catalyzed asymmetric intermolecular hydroamination reaction. ${ }^{3 \mathrm{~b}}$ In the context of metallocene hydroamination catalysts, worth noting is the key contribution of the group of Sadow that reported, in 2011, a very active and enantioselective, non-epimerizable $C_{1}$-symmetric, cyclopentadienylbis(oxazolinyl)borate yttrium catalyst such 2 (Scheme 1) for the formation of various gem-disubstituted pyrrolidines in high yields $(95-100 \%)$ and enantiomeric purity (89-96\% ee). ${ }^{4}$ Mechanistic investigations suggest that these state-of-the-art Group III hydroamination catalysts operate through distinct mechanistic pathways. As schematically depicted in Scheme 1, cyclohydroamination reactions catalyzed yttrium complexes $\mathbf{1}$ and $\mathbf{2}$ are proposed to proceed by a stepwise $\sigma$-insertive pathway (involving migratory 1,2-alkene insertion into the $\mathrm{Y}-\mathrm{N} \sigma$-bond followed by aminolysis at the thus generated $\mathrm{Y}-\mathrm{C} \sigma$-bond) and a concerted proton-assisted non-insertive pathway (evolving concomitant $\mathrm{C}-\mathrm{N} / \mathrm{C}-\mathrm{H}$ bond formation at an yttrium amido-/amino-alkene species via a multi-center-transition state) respectively. These mechanisms have found echo in other related metal-catalyzed hydroamination reactions. Despite these advances, there is still a need for improvement as these systems suffer from some moderate stereoselectivity and/or require a large excess of alkene under forcing reactions conditions. Efforts that have been conducted in this direction in the last five years using chiral metallocene and non-metallocene catalysts will be highlighted below, as well as those involving chiral late-transition metal elements for comparison.

Scheme 1. State-of-the-art Group III catalysts for asymmetric alkene hydroamination and proposed operating mechanisms.

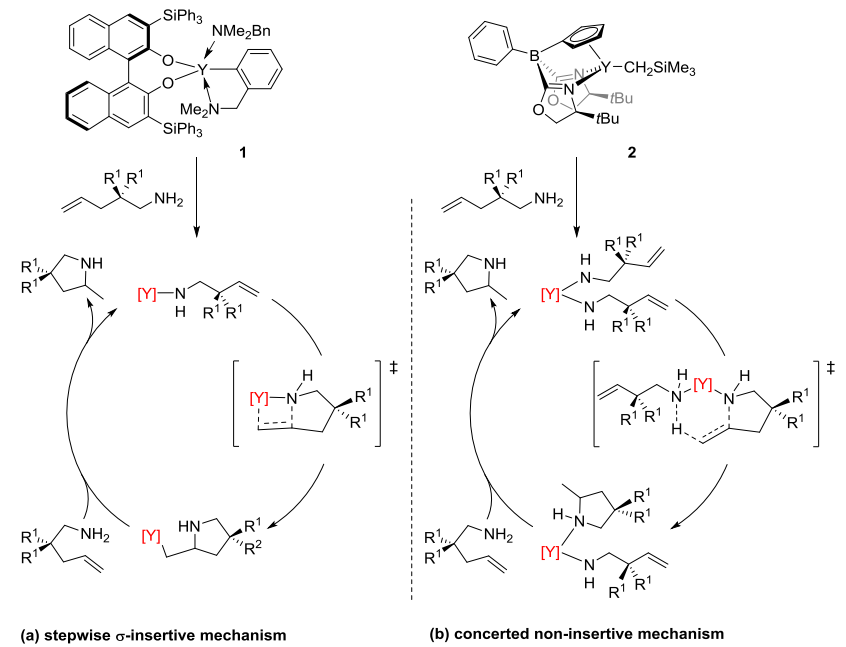

\subsection{Recent developments with Group III elements}

In order to circumvent some of these drawbacks associated with triphenylsilyl-substituted binaphtolate rare-earth alkyl complexes in intermolecular reactions, the group of Hultzsch has recently developed a series of $C_{1}$-symmetric rare-earth ( $\mathrm{Ln}$ $=\mathrm{La}, \mathrm{Lu}, \mathrm{Y}$ ) alkyl complexes based on sterically bulky chiral NOBIN-derived aminodiol proligands and studied their catalytic efficiency in intra- and intermolecular alkene hydroamination. ${ }^{5}$ Unfortunately, these complexes turned out to be slightly less active and enantioselective than their previous- ly reported $C_{2}$-symmetric binol-derived complexes, certainly due to the presence of the additional amine in the ligand framework as suggested by the authors. Contributions in the area of chiral rare-earth non-metallocene complexes are also be gained by the groups of Livinghouse ${ }^{6}$ and $\operatorname{Ward}^{7}$ using $C_{2^{-}}$ symmetric complexes derived from chiral $N$-substituted binaphthylamine and bis(oxazolinylphenyl)amide (BOPA) ligands respectively. These systems still require improvements to compete with the Hultzsch and Sadow catalysts (1 and 2). Surprisingly, the major developments of the last five-years arise from chiral half-metallocene complexes, that were the subject of much less effort in contrast to non-metallocene complexes that were the main focus of the hydroamination community. In 2014, the group of Yang reported the synthesis of a novel chiral silicon-linked tridentate amido-indenyl ligand from indene and enantiopure 1,2-cyclohexanediamine and its structurally-defined yttrium bis(trimethylsilyl)amido complex 3 (Scheme 2, top). ${ }^{8}$ As catalyst at low loading, this complex is efficient for the formation of various gem-disubstituted pyrrolidines and piperidines in high conversion and high ee values from primary amines tethered to monosubstituted alkenes or styrene-type alkenes (Scheme 2, top). It is worth noting that this constrained geometry complex provides some of the highest ee values to date, $97 \%$ and $72 \%$, for the formation of a five-membered ring and a six-membered ring respectively in the field of rare-earth-catalyzed hydroamination. The high enantioinduction observed may result from the presence of three chiral elements in the complex as revealed by solid-state characterization, although epimerization of the chiral planarity may not be excluded in the catalytic conditions as suggested by X-ray analysis of the erbium congener.

Scheme 2. Selected Group III chiral complexes for asymmetric intra- and intermolecular alkene hydroamination. 


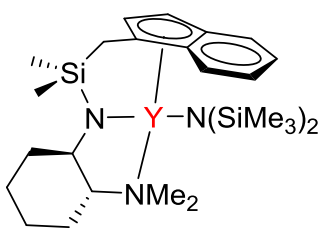

$\mathrm{R}^{2} \overbrace{\mathrm{n}}^{\mathrm{NH}_{2}}$
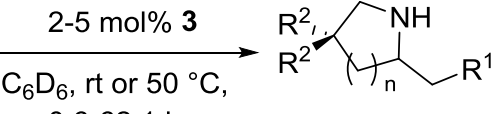

$0.6-62.1 \mathrm{~h}$

$\mathrm{R}^{1}=\mathrm{H}, \mathrm{Ph}$,

$>95 \%$ conv.

$\mathrm{R}^{2}=\mathrm{Me}, \mathrm{Ph},-\left(\mathrm{CH}_{2}\right)_{5^{-}}$

$\mathrm{n}=1,2$

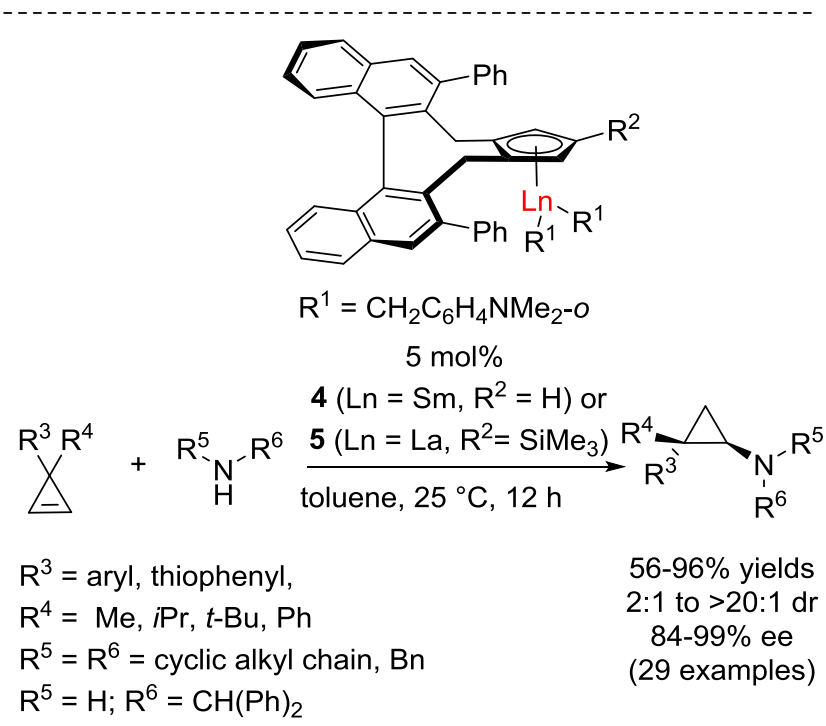

In 2016, motivated by their successful work on the enantioselective $\mathrm{C}-\mathrm{H}$ bond addition of pyridines to olefins catalyzed by a novelty-developed family of chiral halfsandwich rare-earth complexes bearing chiral binaphthylsubstituted monocyclopentadienyl ligand, ${ }^{9}$ the group of Hou elegantly investigated the applications of this family of complexes in the enantioselective catalytic hydroamination of meso 3,3-disubstituted cyclopropenes. $^{10}$ This desymmetrization protocol catalyzed by well-defined rareearth alkyl complexes $\mathbf{4}$ or $\mathbf{5}$ provides a variety of chiral aminocyclopropanes from various 3-methyl-3'-arylcyclopropene and cyclic and acyclic secondary amines (such as morpholine, pyrrolidine, isoindoline...) in moderate to high yields and excellent enantio- (up to $99 \%$ ee) and diastereoselectivity (up to $>20: 1 \mathrm{dr}$ ) under mild reaction conditions (Scheme 2, bottom). Optimization studies reveal that the bulkier lanthanum complex 5 is more enantioselective than 4 for acyclic amines meanwhile the yttrium analogue of $\mathbf{4}$ is the best catalyst for the addition of primary amines. These studies highlight that catalyst activity and reaction selectivity are sensitive to the metal ion and ligand bulkiness. This report represents the first application of chiral half-sandwich rareearth alkyl complexes in hydroamination catalysis and brightly illustrates the promising future of these unique complexes in asymmetric atom-economic reactions. ${ }^{11}$

\subsection{Recent developments with Group IV elements}

Early 2013, after some initial reports in $2011,{ }^{12}$ the group of Sadow described, a full account of their investigations into the development of neutral Group IV-based bis(amido) complexes (Ti, Zr, Hf) supported by chiral cyclopentadienylbis(oxazolinyl)borate ligands for asymmetric hydroamination of aminoalkenes. ${ }^{13}$

Scheme 3. Chiral cyclopentadienylbis(oxazolinyl)borate zirconium bis(dimethylamido) complex for asymmetric hydroamination of aminoalkenes (a) and aminodialkenes.

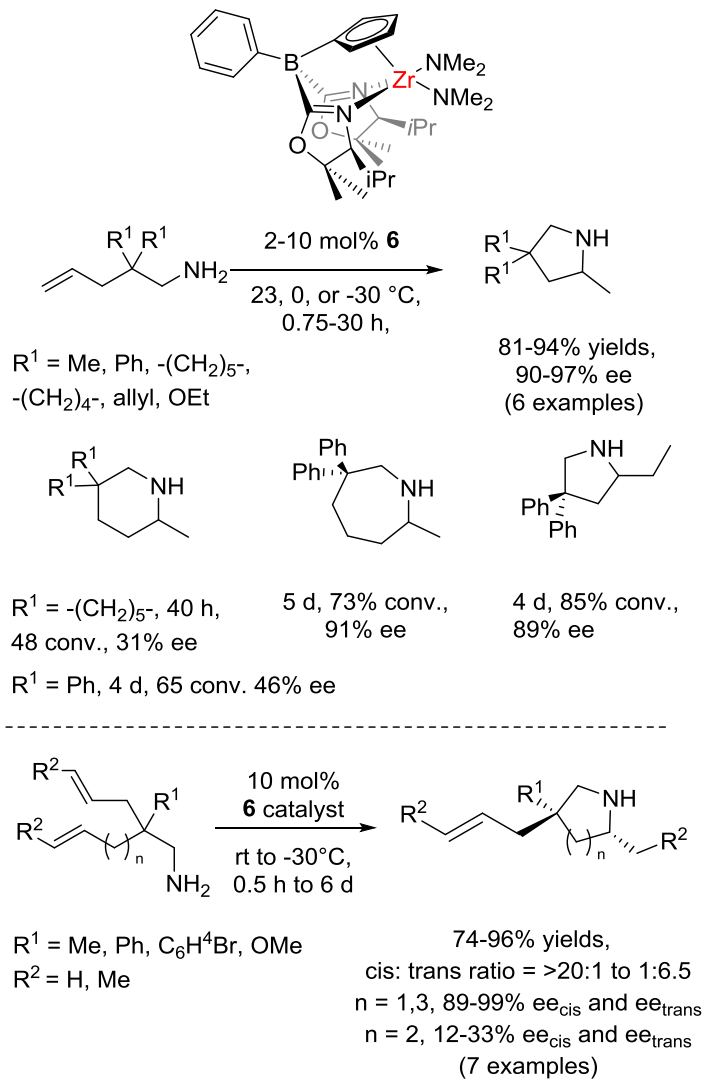

As mentioned above, this ligand scaffold has already been successful for the design of very active and highly enantioselective hydroamination catalysts derived from yttrium metal (complex 2, Scheme 1). ${ }^{4}$ These chiral complexes are efficient catalysts for the cyclohydroamination of gemdisubstituted aminoalkenes affording five-, six- and even seven-membered ring compounds in moderate to high yields and with ee up to $99 \%$ at room temperature and below (Scheme 3, top). These systems display noteworthy features regarding the influence of ancillary ligands, metal center, ring size, $N$-deuteration of substrates on cyclization rate, enantioselectivity and sense of stereoinduction. The tridentate structure of the chiral cyclopentadienylbis(oxazolinyl)borate ligand and the two $\mathrm{NMe}_{2}$ ligands are primordial to the catalytic activity as the mono-oxazoline or -amide analogue complexes are ineffective as catalysts. As a general trend, the zirconium complex 6 based on the valine-derived ligand is more active and/or enantioselective than those based on hafnium and titanium or its analogue derived from tert-leucine. As usually noticed, the rate and enantioinduction in the cyclization of aminohexenes catalyzed by these systems are significantly lower than those of aminopentenes. Surprisingly, supported by the same chiral ligand, complex $\mathbf{6}$ and its yttrium alkyl homologue 2 give enantiorenriched pyrrolidines with 
opposite absolute configuration. Moreover, in contrast to 2 for which the ee values decrease with the $\mathrm{N}$-deuteration, $\mathrm{N}$ deutereo-aminoalkenes provides cyclized products with higher ee's values than those from $N$-proteo-aminoalkenes under identical reaction conditions. Secondary amines tethered to alkenes are only cyclized upon addition of a catalytic amount of primary amines and with a low conversion (ca 2.5 catalyst turnover). The isotopic effect on stereochemistry and the reactivity of secondary amine suggest that a $\mathrm{N}-\mathrm{H}$ bond is involved in the enantiodetermining $\mathrm{C}-\mathrm{N}$ bond formation.

Scheme 4. Proposed hydroamination mechanism for chiral cyclopentadienylbis(oxazolinyl)borate zirconium bis(dimethylamido) complex 6.

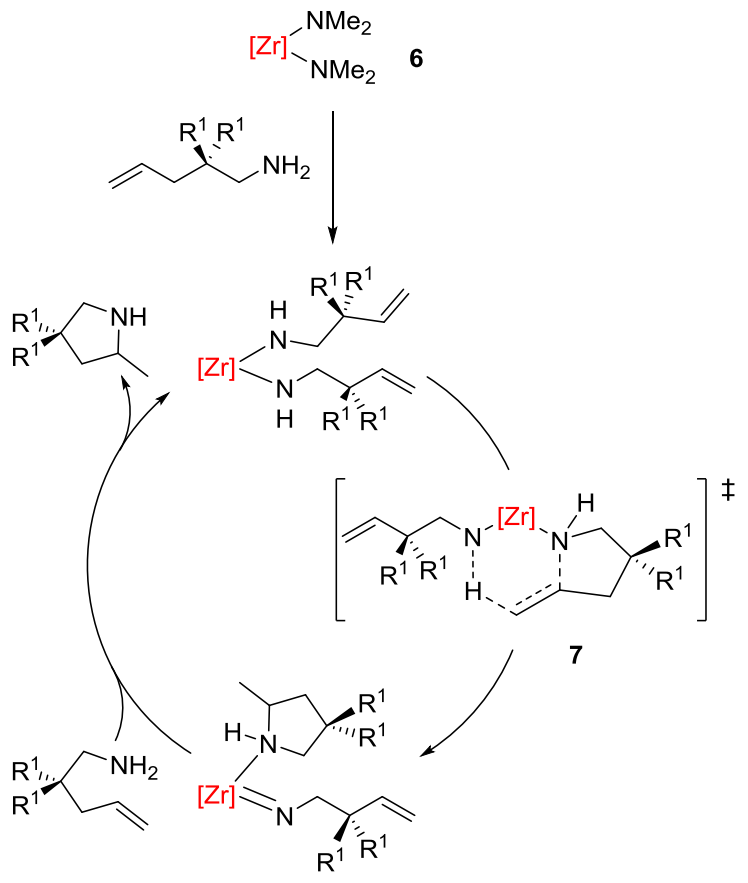

All of these features, coupled to the observations of an empirical second order rate law with respect to catalyst and aminoalkene concentration, a significant primary KIE and a large and negative $\Delta S^{*}$ value suggest that the reaction might proceed by concomitant $\mathrm{C}-\mathrm{N} / \mathrm{C}-\mathrm{H}$ bond formation at a zirconium center bis(primary amidoalkene) species through a multi-center transition state (7) as schematically represented in Scheme 4.

More recently, the efficiency of chiral cyclopentadienylbis(oxazolinyl)borate zirconium bis(dimethylamido) complex $\mathbf{6}$ was further extended to the stereoselective desymmetrization of symmetrical aminodialkenes affording pyrroline-, piperidine- or azepanemolecules in high to moderate yields and with low to high diastereo- and enantioselectivity at room temperature (Scheme 3 , bottom). ${ }^{14}$ Interestingly, the favored absolute configuration of both stereogenic centers can independently be controlled by the ancillary ligand and the reaction conditions. Indeed, the absolute configuration of the stereocenter generated by the $\mathrm{C}$ $\mathrm{N}$ bond formation is under catalyst-control while the absolute configuration of the stereocenter resulting from the substrate desymmetrization can be tuned by the reaction temperature and/or initial aminodialkene concentration. Decreasing the temperature or increasing the substrate concentration favors the trans over the cis isomer and the synergic combination of both effects can remarkably alter the cis: trans ratio from 12:1 to $1: 4.5$ while maintaining high enantioselectivity for both diasteromers. The trans diastereoselectivity over the cis can also be improved by a primary amine additive. The isotopic substitution of aminodialkene $\mathrm{N}-\mathrm{H}$ bond by $\mathrm{N}-\mathrm{D}$ bond has a positive effect on the cis diastereoselectivity and ee's values. To rationalize the selectivity dependence on aminodialkene concentration, the authors propose a closely related mechanism to the one displayed in Scheme 4, for which the structure of the six-membered transition state of the rate and stereodetermining step is altered by the substrate concentration and this alteration influences the diastereoselectivity outcome of the desymmetrization process without changing the enantioinduction.

In 2014, encouraged by their previous work on multinuclear zinc complexes derived from ortho-aminated salicylaldehyde which displayed high catalytic activity in alkene cyclohydroamination, ${ }^{15}$ the group of Hussein and Blechert examined the application of bimetallic complexes of zinc, copper and zirconium supported by chiral salen-type ligands of type $\mathbf{L}_{\mathbf{1}}$ in the enantioselective intermolecular hydroamination of unactivated alkenes (Scheme 5). ${ }^{16}$ Optimization studies reveal that the combination of salen ligand $\mathbf{L}_{\mathbf{1}}$, $\mathrm{ZnMe}_{2}$ and $\mathrm{Zr}\left(\mathrm{NMe}_{2}\right)_{2}(15 \mathrm{~mol} \%)$ in a $1: 1.5: 1.5$ ratio is an efficient catalytic system for the cyclization of gemdisubstituted aminopentenes and -hexenes at $80^{\circ} \mathrm{C}$ with full conversion, leading to the formation of the corresponding products in moderate to high ee's (Scheme 5). The heterobimetallic combination is essential for catalytic efficiency as homometallic $\mathrm{Zn}$ and $\mathrm{Zr}$ systems afford no conversion and lower ee respectively. The absolute configuration of the product is governed by the chirality of the 1,2diaminocyclohexane unit of the ligand while that of the 1phenylethylamine moiety has little influence on the ee outcome. From these observations and the fact that the use of chiral Jacobsen ligand instead of $\mathbf{L}_{\mathbf{1}}$ leads to an inactive system, the zirconium atom is suggested to coordinate to a rigid metalloligand having a salen-zinc core and forms a chiral metalloligand zirconium bis(dimethylamido) complex. Noteworthy are the higher ee's values achieved for the sixmembered ring compounds in contrast to the five-membered ring. These values obtained for six-membered rings are the highest values ever reported for the formation of such ring size by hydroamination reaction. This heterobimetallic catalytic system, which unfortunately is poorly selective for fivemembered rings is complementary to the Sadow's zirconium complex 6 described above.

Scheme 5. Chiral heterobimetallic $\mathrm{Zn}-\mathrm{Zr}$ complexes for asymmetric cyclization of aminoalkenes. 


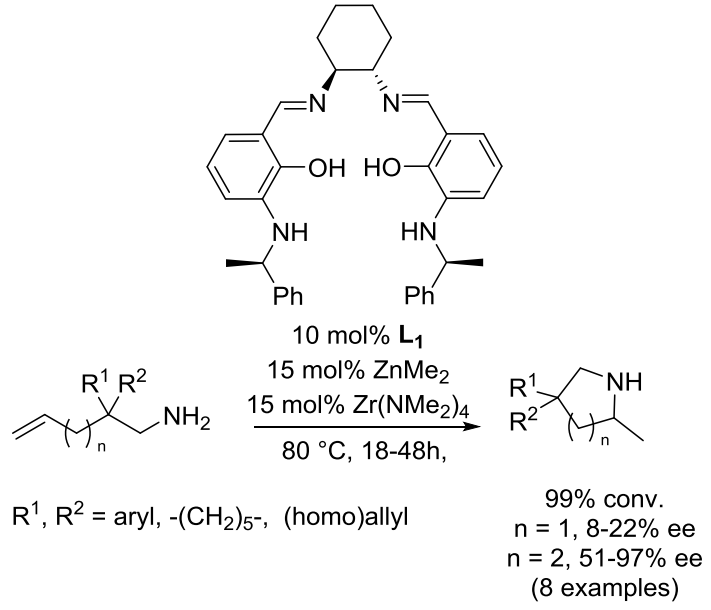

In the area of non-Cp-based Group IV catalysts, Tang, Xie et al. have reported a novel and highly enantioselective family of neutral zirconium dibenzyl complexes stabilized by chiral tridentate $O, N, O$-chelating ligands based on $\beta$-aminoalcohols for the cyclization of primary aminoalkenes under harsh reaction conditions. ${ }^{17}$ Despite displaying lower catalytic activities than complex 6 and the heterobimetallic $\mathrm{Zn}-\mathrm{Zr}$ system described above, high enantioinduction (up to 94\%) are noticed with this new class of catalysts. The group of Schafer has recently illustrated the potential application of the planar chirality of [2.2] paracyclophane to design novel $N, O$-chelating ligands for selective zirconium- and titanium-catalyzed hydroamination reactions, although low to moderate ee's values were obtained $\left(12-68 \%\right.$ ee) ${ }^{18}$ This chiral scaffold should afford great promise for the development of highly stereoselective Group IV-based hydroamination catalysts.

\subsection{Concerning Group V elements}

In 2011, the groups of Johnson, ${ }^{19} \mathrm{Zi}^{20}$ and Hultzsch ${ }^{21}$ independently and successfully demonstrated the potential of applications of Group $\mathrm{V}$ amide complexes $(\mathrm{V}, \mathrm{Nb}, \mathrm{Ta}$ ) supported by $N, N, O, O-, N, O-$, or $O, O$-chelating ligands at axial or center chirality in asymmetric alkene cyclohydroamination of primary amines (and also hydroaminoalkylation, vide infra). To the best of our knowledge and despite promising enantioselectivities (up to $81 \%$ ) obtained nevertheless under harsh reaction conditions, there has been no subsequent report of enantioselective Group V-catalyzed hydroamination of unactivated alkenes.

2.5 Highlights for late transition metal element- promoted enantioselective alkene hydroamination

Concomitantly to these catalyst developments from Group III and IV, significant efforts have also be devoted to the design of efficient late d-block metal catalyst systems for asymmetric alkene hydroamination. These metals should offer great opportunities for the development of competitive systems with a broader scope, higher polar functional group tolerance and stereoinduction. Over the last five-year period, despite some notable progresses with gold-, palladium- and iridium-based systems,${ }^{22}$ the more striking advances in the field unquestionably emerge from the copper chemistry through a novel umpolung electrophilic amination strategy for $\mathrm{C}-\mathrm{N}$ bond formation alternative, and mechanistically distinct, to the classical hydroamination approaches encountered up to now. In
2013, the groups of Hirano/Miura and Buchwald elegantly exploited the well-known chiral diphosphine-based copper hydride chemistry and the electrophilic character of hydroxylamine esters to propose a copper-mediated formal intermolecular hydroamination of arylalkenes and $O$ benzoylhydroxylamines in the presence of hydrosilane with exclusive Markovnikov regioselectivity and high enantioinduction under mild reaction conditions. ${ }^{23,24}$ The massive research activity from the Buchwald group in this area has masterfully demonstrated the impressive, and inequivalent, wide scope and high stereocontrol of the original reported catalytic system $(R)$-DTBM-SEGPHOS $\left.\cdot \mathrm{Cu}(\mathrm{OAc})_{2}\right)$ thanks to, inter alia, its subsequent improvements $\left(\mathrm{PPh}_{3}\right.$ and/or $\mathrm{tBuOH}$ additive, electrophilic nitrogen partners bearing a 4(dimethylamino)benzoate moiety). ${ }^{25}$ This $(R)$-(or (S))-DTBMSEGPHOS-CuH-based methodology was effectively applied to the formal hydroamination of a diverse array of olefin classes (cis/trans- $\beta$-substituted and $\beta, \beta$-disubstituted arylarenes, 1,1-dialkylsubstituted alkenes, symmetrical and unsymmetrical internal alkenes, vinylsilanes, alkenyl 1,8diaminonaphthyl boronates) and a variety of amine transfer agents (monoalkyl-, monoaryl- and dialkylamine) under high levels of chemo-, regio-(Markovnikov or anti-Markovnikov) and stereocontrol (Scheme 6, top). It affords a straightforward and selective route to important and structurally diverse molecular building blocks with a range of functional groups and in high enantiopurity. The incorporation of this methodology in tandem/relay catalysis processes underlines further its tremendous versatility and synthetic value. ${ }^{26}$

Deep mechanistic investigations show, as illustrated in Scheme 6 (bottom), that the reaction is likely to proceed by (1) regioselective and enantio-determining migratory 2,1-insertion of the alkene into an in situ generated and monomeric $\mathrm{Cu}(\mathrm{I})$ hydride species, (2) stepwise stereoretentive electrophilic amination of the resulting alkyl $\mathrm{Cu}(\mathrm{I})$ that lead to $\mathrm{C}-\mathrm{N}$ bond formation and $\mathrm{Cu}(\mathrm{I})$ carboxylate intermediate as the catalyst resting state and (3) rate-limiting $\sigma$-bond metathesis to regenerate the active catalyst. ${ }^{25 \mathrm{~g}, \mathrm{~h}, 27}$ The initial elementary step of the catalytic cycle, namely the olefin hydrometalation, is in strong contrast with the Group III, IV and V element-based hydroamination catalysts for which the reactivity is triggered by the deprotonation of the amine functionality. These orthogonal activation modes lead to ensuing and distinct rate- and stereo-determining steps. Although this DTBM-SEGPHOS$\mathrm{CuH}$-hydroamination methodology is far ahead of any other reported hydroamination process in terms of scope, functional group diversity and stereoselectivity and has, up to now, no rival that shows up, its overall atom and step efficiency diverge from the original concept of hydroamination.

Scheme 6. State-of-the-art copper catalytic system, $(R)-($ or $(S))$-DTBM-SEGPHOS-CuH, for regio- and enantioselective formal hydroamination of an array of olefin classes and its catalytic cycle. 

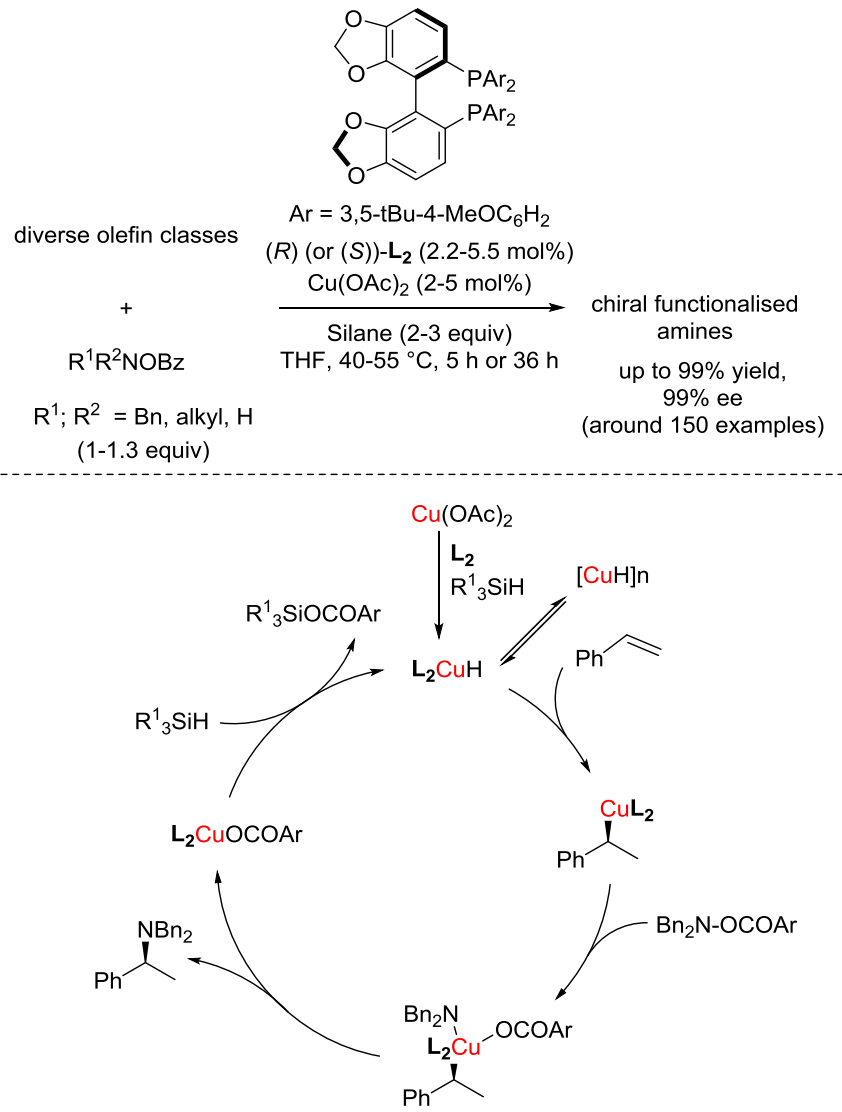

\section{HYDROAMINOALKYLATION}

\subsection{Introduction}

Use of early-transition metal in hydroaminoalkylation catalysis was discovered by Maspero in 1980 for the intermolecular reaction of secondary alkyl amines and diverse alkenes at high temperature in the presence of homoleptic dimethylamidoniobium, -tantalum or -zirconium complexes. ${ }^{28}$ A few years later, Nugent evidenced reversible cyclometalation in earlytransition metal dialkylamido complexes at high temperature, thanks to deuterium labeling studies. ${ }^{29}$ These early studies suggested formation of a metallaaziridine as key intermediate for the subsequent $\mathrm{C}-\mathrm{C}$ bond creation by alkene insertion into the metal-C bond. Since these preliminary results, significant progress has been devoted to the development of this reaction with Group IV and V elements which has been comprehensively detailed in two recent reviews. ${ }^{2}$ Although results already go back longer, here will be emphasized the discovery of chiral ligands which allowed enantioselective hydroaminoalkylation reaction to be performed with Group V metals. To the best of our knowledge, such reactivity has not been yet reported by the use of Group IV elements, but new ligands have been discovered that allowed many improvements in terms of reaction conditions and scope. Will be also mentioned the very recent use of Group III elements and transition metals for this reaction. Of note, hydroaminomethylation reactions can also be efficiently performed by a tandem process involving a hydroformylation reaction combined with a reductive amination mostly promoted by rhodium-based catalysts. Nevertheless, scalemic derivatives cannot yet be achieved by these reactions type whose mechanism differs of course from that involving the metals of groups III-V. This reactivity is outside the scope of this article and has been highlighted in recent reviews. ${ }^{30}$

\subsection{Recent developments with Group V elements,}

\subsubsection{Enantioselective developments}

Hartwig and Herzon reported in 2007 the catalytic hydroaminoalkylation of unactivated olefins with $\mathrm{N}$ alkylanilines in the presence of $\mathrm{Ta}\left(\mathrm{NMe}_{2}\right)_{2}$ delivering the branched product after several hours under high temperature $\left(160-165{ }^{\circ} \mathrm{C}\right){ }^{31}$ An intramolecular procedure yielded $\mathrm{N}$-(2methylcyclohexyl)aniline albeit with no diastereoselectivity. Further use of $\left[\mathrm{TaCl}_{3}\left(\mathrm{NEt}_{2}\right)_{2}\right]_{2}$ with less donating halide ligands allowed not only the same transformation to be run under much less drastic conditions $\left(90^{\circ} \mathrm{C}\right)$ but also the conversion of dialkylamines. ${ }^{32}$ Inspired by this work, Schafer and coworkers reported the synthesis of mono(amidate)-tantalum tetrakis(dimethylamido) complexes, as active catalysts specifically for the reaction between terminal (and internal) alkenes and arylalkyl amines or dialkylamines. ${ }^{33}$ Of note is the reactivity of $N$-benzyl methylamine for which insertion occurred exclusively at the benzylic position. Preparation of the chiral complex 8 (Scheme 7, top) possessing the biphenyl framework as $C_{2}$-symmetric tethered ligand occurred straightforwardly by protonolysis with $\left[\mathrm{Ta}\left(\mathrm{NMe}_{2}\right)_{5}\right]$ giving rise to a pseudotrigonal bipyramidal tantalum center with a bidentate chelation $(\kappa O$, $\left.\kappa O^{\prime}\right)$ as evidenced by X-ray crystallography and NMR data.

Scheme 7. Selected Group V chiral complexes for asymmetric intermolecular hydroaminoalkylation.

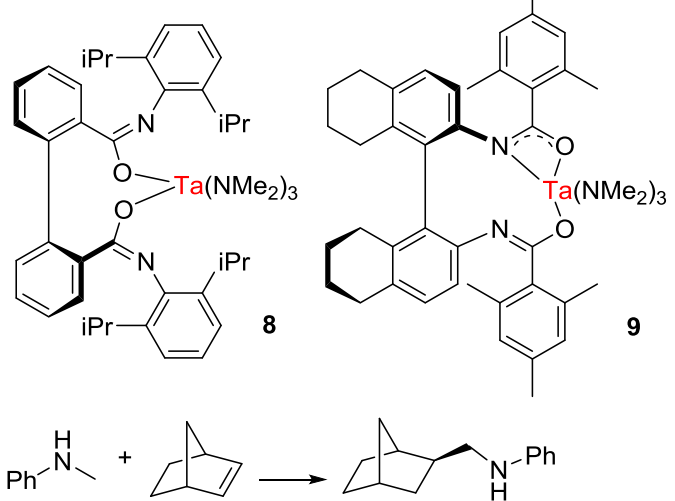

$8,10 \mathrm{~mol} \%, 130^{\circ} \mathrm{C}, 46 \mathrm{~h}, 80 \%, 61 \%$ ee

$9,5 \mathrm{~mol} \%, 160^{\circ} \mathrm{C}, 48 \mathrm{~h}, 85 \%, 91 \%$ ee
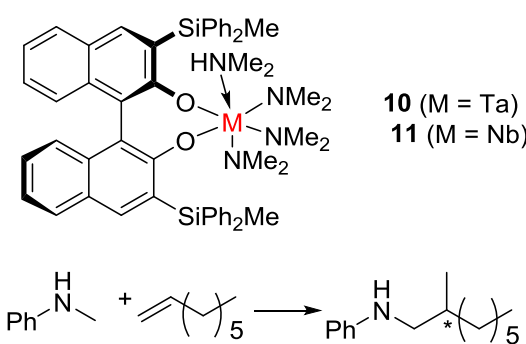

$10,5 \mathrm{~mol} \%, 150^{\circ} \mathrm{C}, 14 \mathrm{~h}, 88 \%, 72 \%$ ee

$11,5 \mathrm{~mol} \%, 150^{\circ} \mathrm{C}, 7 \mathrm{~h}, 85 \%, 72 \%$ ee

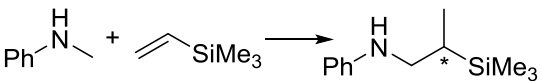

$11,5 \mathrm{~mol} \%, 100^{\circ} \mathrm{C}, 48 \mathrm{~h}, 82 \%, 98 \%$ ee 
Precatalyst $\mathbf{8}$ allowed enantioselective catalytic $\alpha$-alkylation of arylalkyl amines to be performed as first example for such reactivity delivering exclusively the chiral branched amines in high yield (at $130{ }^{\circ} \mathrm{C}$ ) with up to $61 \%$ ee. The following year, the group of $\mathrm{Zi}$ reported the synthesis of analogous Group V metal amidates from homoleptic niobium and tantalum amidates with $C_{2}$-symmetric binaphthylamidate-type ligands (9, Scheme 7 (top), and its unsaturated analogue). ${ }^{34,35}$ For these complexes, X-ray diffraction analyses showed, in each case, $\sigma$-bound coordination of the metal to one nitrogen and two oxygen atoms from the ligand, and three nitrogen atoms from dimethylamino groups in distorted octahedral geometry. The same range of substrates was engaged and niobium complexes displayed no reactivity. On the contrary tantalum derivatives proved to be highly enantioselective catalysts providing branched amines in up to $91 \%$ ee, after two days reaction at $160{ }^{\circ} \mathrm{C}$.

The last example of Group V mediated asymmetric catalysis was described by Hultzsch and his group who reported the synthesis of enantiomerically pure tantalum and niobium amido complexes bearing 3,3'-silylated binaphtholate ligands (10 and 11 in Scheme 7, bottom). Isostructural complexes were recovered showing, thanks to X-ray crystallography, slightly distorted trigonal bipyramidal geometry. ${ }^{21}$ Hydroaminoalkylation activity of these species was very dependent on the steric bulk from the silyl groups, and alkylated amines could be isolated from reactions with niobium-based catalysts, for the first time. Scope for the reaction was mainly tested in the presence of arylmethyl amines, and the niobium catalysts were more active than the analogous tantalum derivatives (at $140^{\circ} \mathrm{C}$ ) with both complexes yielding the targeted branched amines in about $70 \%$ ee. The highest value described up to date (98\% ee) was obtained with a niobium chiral complex 11 operating at $100^{\circ} \mathrm{C}$ for the insertion of trimethyl(vinyl)silane. ${ }^{36}$ Hydroaminoalkylation of $\mathrm{N}$ benzylmethylamine was also successful with these catalysts but insertion occurred, contrarily to what was observed with tantalum-amidate complexes, ${ }^{33}$ after activation of the methyl and not the benzylic group of the nitrogen atom. The general mechanism for the hydroaminoalkylation catalyzed by Group $\mathrm{V}$ elements is represented in Scheme 8, with the reversible formation of the metallaaziridine ${ }^{37}$ by $\mathrm{C}-\mathrm{H}$ activation of the bisamide as key step. Olefin insertion, followed by protonolysis of the $\mathrm{C}-\mathrm{M}$ bond and amido exchange deliver the branched alkylated amine.

Scheme 8. Proposed mechanism of intermolecular hydroaminoalkylation for Group V catalysts.

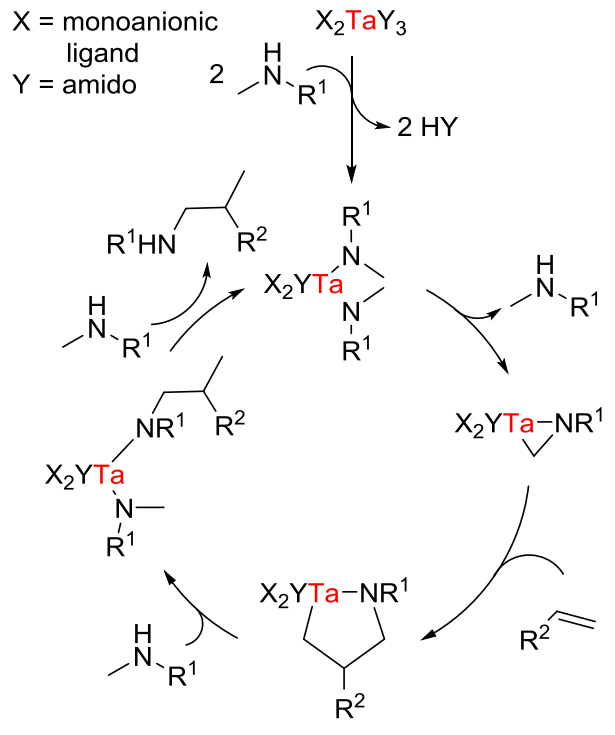

Hultzsch et al. conducted mechanistic studies on their metal binaphtholate complexes and concluded from reaction kinetics, kinetic isotope effects and isotopic labeling studies that the formation of the key metallaaziridine occurred via a nondissociative process leading to a six-coordinate species, facilitating intramolecular protonolysis of the intermediary formed azacyclopentametallacycle. ${ }^{36}$ Very few example of intramolecular hydroaminoalkylation with Group V elements ${ }^{31}$ and no enantioselective version are known, since aminoalkene substrates are prone to yield preferentially hydroamination products in these conditions.

\subsubsection{Recent (nonenantioselective) developments}

As far as we are aware, there has been no other contribution concerning the description of enantioselective hydroaminoalkylation with Group V catalysts since 2012. Studies have instead been devoted to the development of new, more active catalytic systems that allow the transformation of a wider range of substrates at lower temperatures. Schafer reported the efficient use of $\mathrm{TaMe}_{3} \mathrm{Cl}_{2}$ as favorable precatalyst for the preparation of the key tantalaziridine intermediate thanks to easy methane elimination. With this species indeed, catalysis could occur at $110{ }^{\circ} \mathrm{C}$ and various alkenes (including 1,1-disubstituted, internal and trisubstituted olefins, as well as styrene derivatives) were reacted with methylanilines or methylalkyl amines, as demanding substrates. ${ }^{38}$ Most studies are currently looking for an attempt to rationalize the use of specific ligands, as essential parameter greatly influencing the reactivity of the corresponding catalyst, as has been seen, for example, for the conversion of $N$-methyl-1-phenylmethanamine with either amidate or binaphtholate catalysts.

To gain insight into the specific role of the ligand for the complex reactivity, amidate complexes of group $\mathrm{V}$ elements were further investigated as such catalysts family already disclosed high efficiency in enantioselective reactions (12, Scheme 9). Various mono(amidate) tantalum and niobium complexes were thus prepared by introduction of groups with different steric bulk on the nitrogen substituent or incorporation of additional heteroatoms on the ligand backbone. ${ }^{39,40}$

Scheme 9. Tantalum complexes for intermolecular hydroaminoalkylation bearing modular $\mathrm{N}, \mathrm{O}$ chelating ligands. 


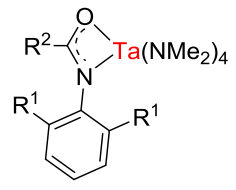

12

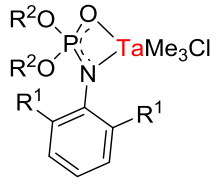

13

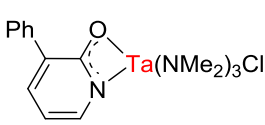

14

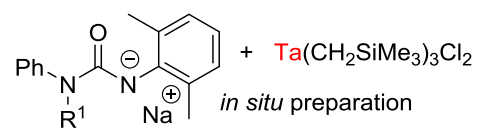

15
Higher reactivity is noticed with the increase of the ligand steric bulk on a benchmark reaction involving $N$-methylaniline with a linear alkene, at least for complexes in which $\kappa^{2}-N, O$ coordination is conserved despite the steric hindrance. Introduction of other heteroatoms on the ligand backbone did not improve catalytic results, which is on the other hand the case for a ligand bearing an ortho-methoxyphenyl substituent on the nitrogen atom, as possibly labile donor atom. Of note, the niobium complexes proved efficient for this reaction, contrarily to the results obtained by the group of $\mathrm{Zi}^{34,35}$ Furthermore, these niobium complexes are less reactive than the tantalum counterparts, in opposition to the results described by Hultzsch in the binaphtholate series. ${ }^{21,36}$ Mechanistic investigations have elucidated the kinetics of the hydroaminoalkylation reaction catalysed by amidate complexes ${ }^{40}$ and their synthetic interest has been demonstrated by their propensity to catalyze the alkylation of cyclic amines with terminal olefins or norbornene. $^{41}$ Alkylated piperidines, azepanes and piperazines were obtained, albeit after several days of heating at $165{ }^{\circ} \mathrm{C}$, but with high isolated yield and perfect regioselectivity towards the branched product together with excellent diastereoselectivity. Only monoalkylation products were observed due to high steric constraints and alkylation of 5-membered $\mathrm{N}$ heterocycles remained a limitation for this procedure.

Further efforts towards the development of Group V complexes bearing ligands with enhanced electron-withdrawing properties led to the preparation of phosphoramidate tantalum complexes (13, Scheme 9) from $\mathrm{Cl}_{2} \mathrm{TaMe}_{3}{ }^{42}$ Crystals suitable for X-ray analysis could be obtained revealing a distorted trigonal bipyramidal geometry for the complex with a $\kappa^{2}-N, O$ chelation of the phosphoramidate ligand trans to the axial chloride ligand. A particularly remarkable advance in reactivity was obtained using these catalysts which proved able to activate the hydroaminoalkylation reaction at room temperature, for a wide range of $N$-methylanilines with terminal olefins, or norbornene, to give the branched product after only some 20 hours of reaction. More demanding substrates such as dialkylamines or styrene derivatives could also be converted by slightly enhancing the reaction temperature to $50{ }^{\circ} \mathrm{C}$ or by prolonging the reaction time. In all cases branched products were obtained, even if the regioselectivity ratio varies hugely, depending on the electronic properties of the substituents carried by the aromatic styrene ring. Use of vinyltrimethylsilane as alkylating agent led to the formation of the linear product as main species, contrarily to previous reports ${ }^{31,36}$ highlighting, once again if it was necessary, the high dependence between the catalytic system and the engaged substrates structures.
Replacing the phosphoramidate ligand by a 2-pyridonate motif in the presence of $\left[\mathrm{Ta}\left(\mathrm{NMe}_{2}\right)_{3} \mathrm{Cl}_{2}\right]_{2}$ delivered thermally robust complexes, as in $\mathbf{1 4}$ (Scheme 9), possessing a distorted trigonal bipyramidal geometry with a $\kappa^{2}-N, O$ chelation on the tantalum in the solid state. ${ }^{43}$ This complex displayed particularly high activity for performing hydroaminoalkylation of internal $Z$ - and $E$-alkenes with arylalkyl amines but also dialkylamines, but high temperatures of $145{ }^{\circ} \mathrm{C}$ were nevertheless required for these very challenging transformations. Reactivity is assumed to be due to the hemi-lability of the pyridonate ligand allowing controlled release of steric congestion during the catalysis for these demanding substrates. However, performances were less much lower with terminal alkenes, highlighting that a perfect combination of steric constraints coming from both the substrate and the catalyst (together with its electrophilicity) is necessary for the best catalyst turnover. Further use of commercially available 3-methyl2-pyridone and 2-pyridone led to highly active catalysts to promote the intermolecular hydroaminoalkylation of both terminal and internal olefins. ${ }^{44}$ Comparative kinetic investigations with these systems led to the identification of numerous and intricate off-cycle equilibria, drastically linked to the ligand environments, and specifically to the presence of dimethylamido goups. The practicality of this procedure could be demonstrated by the easy in-situ preparation of the active precatalysts from commercially available stable precursors to synthesize regio- and diastereoselectively branched alkylamines. ${ }^{45}$ The more recent example, from this year, proposed again a facile in situ synthesis of very active tantalum catalyst (15, Scheme 9) from ureate salts and the more thermally stable $\mathrm{Ta}\left(\mathrm{CH}_{2} \mathrm{SiMe}_{3}\right)_{3} \mathrm{Cl}_{2}$ complex. ${ }^{46}$ These complexes allowed the reaction between $N$-methylaniline derivatives and terminal olefins to be almost completed in $2 \mathrm{~h}$, and $5 \mathrm{~h}$ when internal alkenes are concerned. Worth of note is the use, for the first time, of an equimolar amount of both reaction partners in the reaction mixture. However no conversion could be observed by the introduction of less reactive dialkylamines.

\subsection{Recent developments with Group IV elements}

Starting from the early work of Maspero and Nugent ${ }^{29}$ who evidenced reversible cyclometalation in dialkylamido early transition metal complexes, numerous improvements have been then described to perform efficient hydroaminoalkylation (both in its intermolecular and intramolecular version) catalyzed by Group IV elements. The general hydroaminoalkylation catalytic cycle is similar to the one proposed for Group $\mathrm{V}$ species, proceeding by activation of a $\alpha-\mathrm{C}-\mathrm{H}$ bond to form a metallaaziridine complex. As far as we are aware, however, no enantioselective transformation has been described until now. Only recent developments will thus be described here, leading to improved activity, more significant regioselectivity and especially a broadening of the possible engaged substrates scope. The most significant advances have been made in recent years in the development of titanium-based catalysts, after the discovery, about ten years ago, of their ability to promote both intra- and intermolecular reactions. ${ }^{47,48}$ Initial studies in the presence of $\mathrm{Ti}\left[\mathrm{NMe}_{2}\right]_{4}$ or $\left[\mathrm{TiBn}_{4}\right]$ showed promising catalytic activities with these species, with various branched aminoalkanes obtained as major but not unique products. Use of $\left[\mathrm{Ind}_{2} \mathrm{TiMe}_{2}\right]$ greatly improved this selectivity and allowed furthermore reaction with styrene derivatives albeit with a lower selectivity in favour of the branched compounds. ${ }^{48}$ 
In this context, the last five years have seen the development of new titanium catalysts to widen the scope of the hydroaminoalkylation reaction. Considering indeed intramolecular reactions, numerous Group IV elements have also been demonstrated efficient to deliver products from cyclohydroamination reactions; in this context, the control of the chemoselectivity ${ }^{49}$ between both transformations towards targeted hydroaminoalkylation could be achieved in the presence of $\mathrm{N}, \mathrm{O}$-chelating four-membered metallacyclic titanium complexes by focusing on substrate control, i.e. giving rise for instance to a more stable cyclohexyl ring by hydroaminoalkylation instead of the $N$-heterocyclic seven membered ring arising from hydroamination. More recently, the synthesis of a sterically few demanding bis(3-phenyl-2pyridonate) titanium complex has been achieved which proved to be efficient for the preparation of both five- and sixmembered cycloalkylamines (16, Scheme 10). ${ }^{50}$ Diastereoselectivity was partially controlled with this cataytic species (up to 19:1), but only primary aminoalkenes could be transformed. This characteristic led the authors to propose a mechanism through a titanium imido species with the subsequent formation of dimeric imido species, due to the specific presence of the 3-substituted pyridonate ligand. Such species are inactive to promote hydroamination reactions but are assumed to be catalytic species for hydroaminoalkylation transformations via the intermediary formation of bridging metallaaziridine intermediate, as was previously demonstrated with a $\mathrm{Zr}$ pyridonate precatalyst. $^{51}$ From a known bis(amidate)titanium hydroamination precatalyst through $\alpha-C$ $\mathrm{H}$ activation of benzylamine, a bridging titanaaziridine could also be isolated and fully characterized (17, Scheme 10). ${ }^{51}$ Titanaaziridines have further been synthesized and characterized including by X-ray diffraction spectroscopy, by C-H activation of $N$-methylanilines with a sterically demanding $\operatorname{bis}\left(\eta^{5}: \eta^{1}\right.$-adamantylidene pentafulvene) titanium complex (18, Scheme 10). An hydroaminoalkylation product could be formed in the presence of such a titanacycle with 1hexene, proving its key role as intermediate in this transformation. ${ }^{52}$ Such species have also been identified and characterized using surface organometallic chemistry (SOMC) by the group of Basset, by grafting $\mathrm{Zr}\left(\mathrm{NMe}_{2}\right)_{4}$ onto the surface of $\mathrm{SiO}_{2-700}$. Single-site well-defined surface species [ $\Xi \mathrm{Si}-\mathrm{O}$ $\left.\mathrm{Zr}\left(\mathrm{HNMe}_{2}\right)\left(\eta^{2}-\mathrm{NMeCH}_{2}\right)\left(\mathrm{NMe}_{2}\right)\right]$, as azazirconacyclopropane complexes, could be isolated and characterized, ${ }^{53}$ just as the five-membered intermediate issued from treatment with propylene (19 and 20, Scheme 10). In the presence of dimethylamine, release of $\mathrm{N}$-methylisobutylamine occurred with regeneration of the initial metallacycle as a signature of the elementary steps for intermolecular hydroaminoalkylation. ${ }^{54}$ Exploitation of another class of titanium catalysts in the presence of aminopyridinato-type ligands allowed also intramolecular hydroaminoalkylation reactions to be selectively performed, starting specifically from secondary aryl-aminoalkenes (21, Scheme 10).

Scheme 10. Selected Group IV complexes for intra- and intermolecular hydroaminoalkylation reactions.

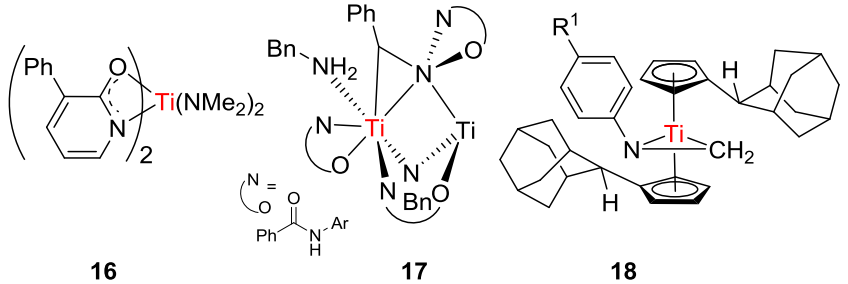

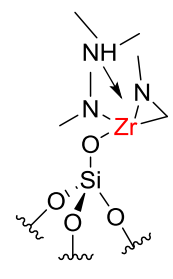

19

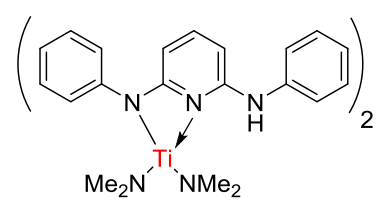

22

20
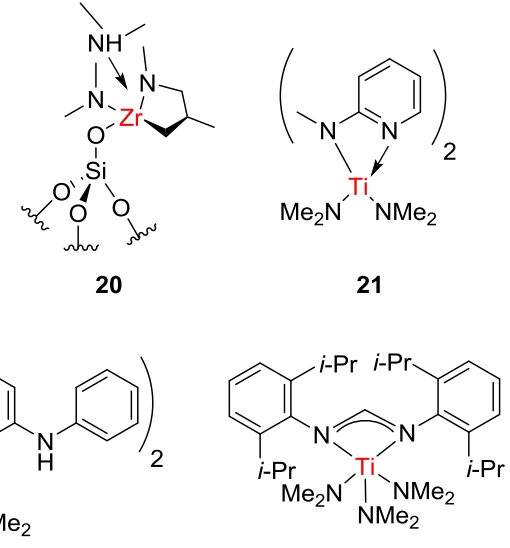

23
Formation of 2-methylcyclohexyl- and cyclopentylamines proved efficient in these conditions although the diastereoselectivity could not be controlled either. ${ }^{55}$ Another issue that was resolved is the control of the regioselectivity in the addition of secondary amines onto styrene derivatives. Use of a 2,6-bis(phenylamino)pyridinato titanium catalyst (22, Scheme 10) led to the preparation of the linear hydroaminoalkylation product with very high selectivities, as a valuable method for the preparation of 3-arylpropylamines as privileged structures possessing biological activities. ${ }^{56}$

Worth mentioning is also the application to the transformation of disubstituted unactivated alkenes and styrene derivatives with secondary amines which could be performed using an easy accessible titanium mono(formamidinate) (23, Scheme 10); very high temperatures are necessary (up to 180 ${ }^{\circ} \mathrm{C}$ ) but high yields and selectivities in favor of the branched compounds are obtained specifically with $N$-methylanilines. ${ }^{57}$ Synthetic utility of these complexes was proven by their successful use in one-pot tandem procedures implying first an intermolecular hydroaminoalkylation and then a subsequent intramolecular Buchwald-Hartwig amination delivering valuable 1,5-benzodiazepines, ${ }^{58}$ 1,5-benzoazasilepines, ${ }^{59}$ and $1,4-$ benzoazasilines. $^{60}$ Very recently, the titanium mono(formamidinate) complex allowed the use of dimethylamine as substrate in hydroaminoalkylation reactions with various (functionnalized) olefins. Precise fine tuning of the reaction conditions, and specifically of the ratio dimethylamine $v s$ olefin, was necessary for ensuring good product yield and selectivity towards monohydroaminoalkylation products, as an alternative to the industrial synthesis of amines through hydroformylation of alkenes and subsequent reductive amination. Branched products were obtained from terminal olefins whereas transformation of styrene derivatives occurred with a poorer regioselectivity. ${ }^{61}$ Dihydroaminoalkylation products were also interestingly accessible by changing the dimethylamine concentration in the solution mixture. 


\subsection{Recent developments with Group III elements}

One of the main limitations of the preceding catalytic systems is the necessary use of primary or secondary amines, for the initial formation of metal (Group IV or V)-amido intermediates through an N-H bond deprotonation. Use of Group III elements recently brought a very elegant solution to this restriction, showing the possibility to promote $\mathrm{C}-\mathrm{H}$ activation of aliphatic tertiary amines and C-C double bond insertion. Developments for performing asymmetric catalysis are not yet known, but Hou and his group reported the preparation of a cationic homoleptic scandium alkyl species and its high reactivity towards $\mathrm{C}-\mathrm{H}$ bonds functionalization, for the description of the first intermolecular hydroaminoalkylation with aliphatic tertiary amines. ${ }^{62}$ For this transformation the half-sandwich scandium dialkylcomplex $\left[\left(\mathrm{C}_{5} \mathrm{Me}_{5}\right) \mathrm{Sc}\left(\mathrm{CH}_{2} \mathrm{C}_{6} \mathrm{H}_{4} \mathrm{NMe}_{2}-O\right)_{2}\right]$ (Scheme 11, top) proved less active as pre-catalyst than $\left[\mathrm{Sc}\left(\mathrm{CHC}_{6} \mathrm{H}_{4} \mathrm{NMe}_{2}-O\right)_{3}\right]$ for steric reasons, and no reaction occurred with the use of other bigger and less electropositive Ln elements. In the presence of one equivalent of $\left[\mathrm{Ph}_{3} \mathrm{C}\right]\left[\mathrm{B}\left(\mathrm{C}_{6} \mathrm{~F}_{5}\right)_{4}\right]$, initial interaction between the scandium metal ion and the nitrogen atom of the tertiary amine occurred followed by deprotonation of an ortho $\mathrm{C}-\mathrm{H}$ bond with the metal alkyl species and the subsequent intermolecular insertion of the $\mathrm{C}-\mathrm{C}$ double bond into the resulting $\mathrm{Sc}-\mathrm{C}$ bond delivering the hydroaminomethylation product.

Scheme 11. Intermolecular hydroaminoalkylation of tertiary amines promoted by scandium-based catalysts

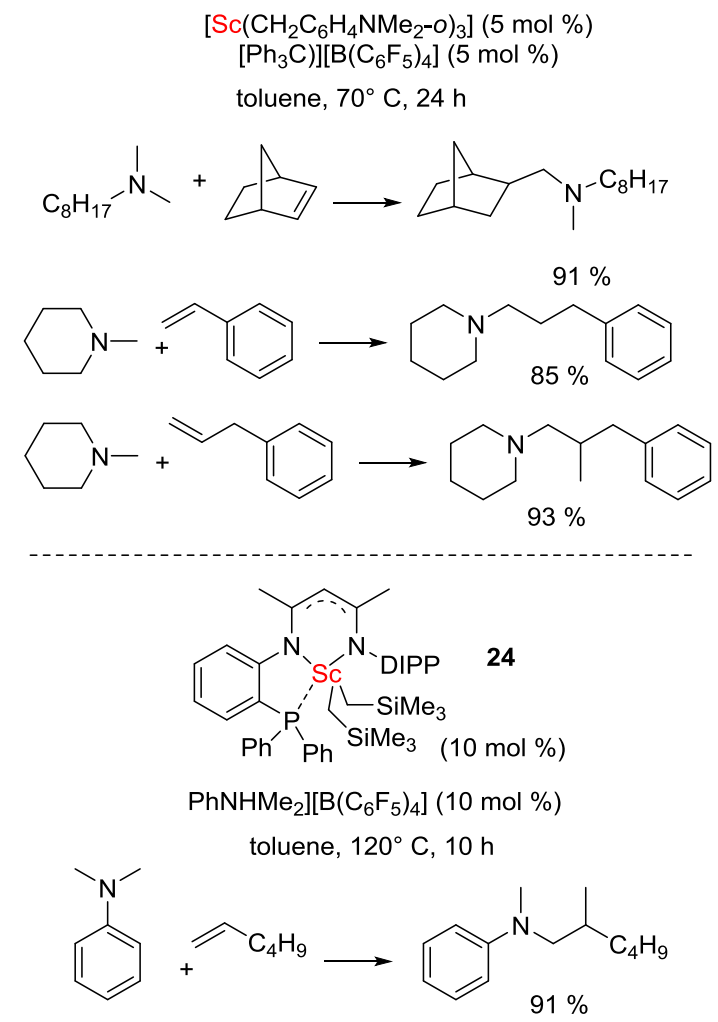

Scheme 12. Proposed mechanism for scandium-catalyzed hydroaminoalkylation

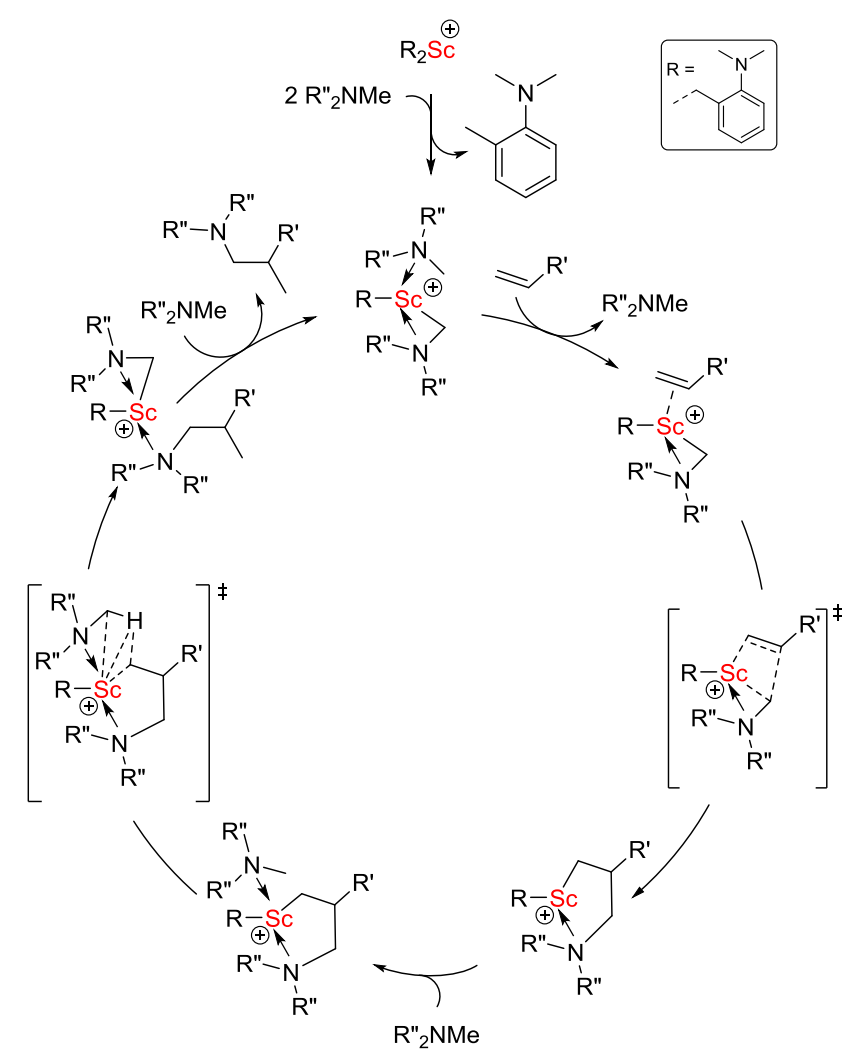

DFT calculations brought important mechanistic insights into this reaction ${ }^{63}$ proposing the formation of an aminecoordinated $\eta^{2}$-azametallacyclic complex as active species and indicating that the regioselectivity is under electronic control from the substrate (Scheme 12).

Various tertiary aliphatic amines (cyclic or acyclic) could react smoothly in high yield with norbornene; reaction with styrene and derivatives delivered exclusively the linear compounds, whereas use of alkyl substituted olefins yielded branched products. $\mathrm{Xu}$ and coworkers widened very recently the scope of the reaction by reacting $N, N$-dimethylanilines to unactivated alkyl olefins affording branched products in high yield. ${ }^{64}$ This reactivity was achieved through the preparation of a catalyst from a $\beta$-diketiminato ligand bearing a rigid phosphine arm and an alkyl scandium precatalyst in the presence of $\left[\mathrm{PhNHMe}_{2}\right]\left[\mathrm{B}\left(\mathrm{C}_{6} \mathrm{~F}_{5}\right)_{4}\right](\mathbf{2 4}$, Scheme 11, bottom).

3.5 Highlights for the use of transition metals in asymmetric hydroaminoalkylation reactions via $\mathrm{Csp}^{3}-\mathrm{H}$ activation

It is obvious, after this description of the last reports dealing with the use of Group III, IV and V catalysts to promote hydroaminoalkylation, that there is room for further developments in the field of enantioselective catalysis, since the last results were obtained almost ten years ago with tantalum and niobium catalysts. Such transformation is also challenging if transition metals are concerned, searching for enantioselective $\mathrm{Csp}^{3}-\mathrm{H}$ activation/C-C bond formation ${ }^{65}$ through formation of carbon-metal bonds in the $\alpha$-position of a nitrogen atom. Concerning addition to conjugated dienes, rhodium catalysis was reported efficient in the presence of monodentate chiral phosphoramidites as ligands for intramolecular allylic $\mathrm{C}-\mathrm{H}$ activation/addition to conjugated dienes, delivering enantiomerically enriched tetrahydropyrroles, tetrahydrofurans and cyclopentane compounds. ${ }^{66}$ 
Early work from Shibata and his group ${ }^{67}$ demonstrated the ability of iridium complexes to perform intermolecular enantioselective hydroaminoalkylation of alkenes through enantioselective cleavage of a secondary $\mathrm{Csp}^{3}-\mathrm{H}$ bond adjacent to the nitrogen atom of 2-(alkylamino)pyridine derivatives. ${ }^{68}$ Highly efficient catalysts, in terms both of yield and selectivity were obtained by preparation of cationic iridium complexes with tolBINAP as the best ligand. The authors proposed the reaction to occur through the enantioselective cleavage of the $\mathrm{C}-\mathrm{H}$ bond adjacent to the nitrogen atom with the pyridyl functionality as directing group, giving rise to the formation of an asymmetric carbon atom. Hydroiridation to alkene followed by reductive elimination delivered the alkylated enantioenriched amine. More recently, they applied this strategy to the enantioselective $\mathrm{C}-\mathrm{H}$ alkylation of $\gamma$ butyrolactams, bearing the pyridyl directing group on the nitrogen atom. ${ }^{69}$ Alkylation could be performed with the same catalytic system and various functionalized terminal olefins, and removal of the pyridyl directing group followed by hydrolysis of the lactams delivered enantioenriched 4-alkylated $\gamma$-amino acids.

A very recent example is worth mentioning for which the $\alpha$ $\mathrm{Csp}^{3}-\mathrm{H}$ bond activation of $\mathrm{N}$-alkyl groups could be performed without any directing group. Ohmura and Suginome described indeed the asymmetric cycloisomerization of 2-alkenyl- $N$ methylanilines into enantioenriched 3-substituted indoline derivatives containing a quaternary carbon center (Scheme 13). ${ }^{70}$ Use of an $\operatorname{Ir}(\mathrm{I})$ complex, chlorobis(ethylene)iridium dimer) as precatalyst in the presence of the $(S)$-DTBMSEGPHOS bearing a very bulky and electron-donating on the phosphorus atoms delivered indoline derivatives in both high yield and enantioselectivity (more than $98 \%$ ee and up to 94 $\%$ yield). Thanks to deuterium-labelling experiments, the authors proposed that oxidative addition of the $\mathrm{C}-\mathrm{H}$ bond of the $N$-methyl group to iridium was the rate-determining step and the mechanism proceeds through a carboridation step followed by reductive elimination.

Scheme 13. Enantioselective Iridium-catalyzed intramolecular hydroaminoalkylation towards indolines.

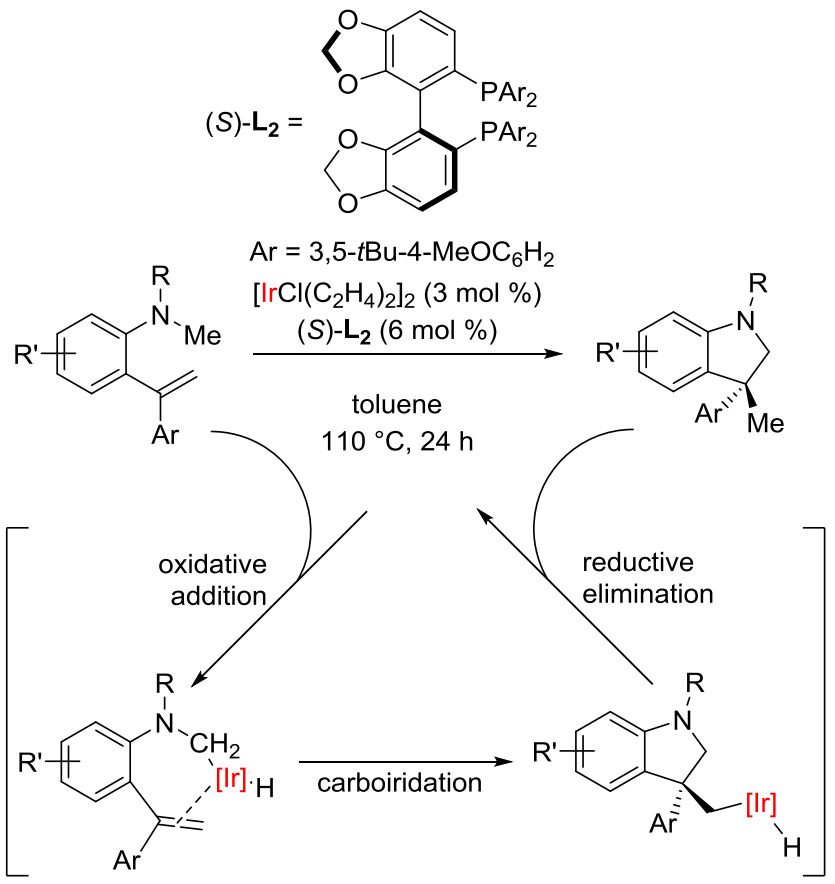

\section{CONCLUSION AND OUTLOOK}

Both hydroamination and hydroaminoalkylation reactions remain areas of great interest in the last few years as demonstrated by the number of recent publications published on these themes. However, and even if many advances are yet to be noted, the challenges highlighted in the introduction are not all fully satisfactorily resolved so far.

Indeed, even if the intramolecular enantioselective hydroamination could already be realized with different catalytic systems from Group III and Group IV elements, which made it possible to obtain highly enantioenriched compounds, it is not yet the case for the intermolecular version which remains a huge challenge to be solved. The achievements concerning the hydroaminoalkylation reaction in this field of enantioselective catalysis are complementary, since as far as we know, it has only been developed with Group V elements and exclusively in intermolecular version. Of particular note is the efficiency of the sterically hindered silylated binaphthol ligands used by Hultzsch and his group, highly valuable for both transformations associated either to yttrium or tantalum/niobium delivering thus scalemic nitrogen-containing heterocycles or arylalkylamines. The last years have seen numerous developments for Group V complexes, highlighting the dependence of the regioselectivity of the reaction on the complex structure. Use of electronwithdrawing ligands possessing also a non-negligible steric bulk allowed hydroaminoalkylation reactions to be performed at much lower temperatures, as low as room temperature, offering thus promise for advances in enantioselective transformations.

Intramolecular asymmetric hydroamination reactions have been performed successfully with chiral Group IV complexes and new catalysts types have even emerged. These transformations are still not developed for the hydroaminoalkylation for which recent developments have nevertheless seen interesting extensions in tandem one-pot procedures, using titanium complexes, for the synthesis of high-value compounds. The main issue of these titaniumpromoted reactions remains the chemoselectivity between both possible intramolecular transformations. While it was resolved so far by the use of biased substrates, the discovery of new ligands of titanium allows now favoring hydroaminoalkylation over hydroamination, even for the formation of 2methylcyclopentylamines. Even if stereoselectivity issues are not yet completely mastered, one can expect the preparation of chiral ligands allowing the enantioselective synthesis of such substrates.

It is largely with Group III complexes that asymmetric hydroamination has been developed over the last 30 years. Reports are now more sporadic, but a new class of metallocene ligands has emerged which delivered already promising results in terms of enantioselectivity values. These last few years have seen the invention of the intermolecular hydroaminoalkylation reaction promoted by cationic complexes of Group III, with tertiary amines, a class of nitrogen compounds obviously not studied until then. The enantioselective version remains to be imagined.

Meanwhile, huge developments have appeared specifically for the enantioselective copper-promoted (formal) hydroamination from electrophilic nitrogen compounds, with 
solutions for an immense structural diversity of both reaction partners, leading to highly enantioenriched nitrogen substrates carrying various functional groups. Use of transition metals to promote enantioselective hydroaminoalkylation with unbiased substrates is less developed, but very recent examples involving iridium-based chiral complexes are also promising in this field.

Nevertheless, and given the current great interest for both the use of easily accessible substrates, and the atom-saving reactions, the future of Group III to $\mathrm{V}$ complexes as safe elements is ensured for the development of both reactions leading to valuable nitrogen products, and the search for enantioselective transformations remains highly relevant.

\section{AUTHOR INFORMATION}

\section{Corresponding Author}

* Jerome.hannedouche@u-psud.fr

* Emmanuelle.schulz@u-psud.fr

\section{ORCID}

Jérôme Hannedouche: 0000-0001-5278-3906

Emmanuelle Schulz: 0000-0002-08444-8825

\section{Notes}

The authors declare no competing financial interest

\section{ACKNOWLEDGMENT}

We thank Univ Paris Sud and CNRS for financial support

\section{REFERENCES}

${ }^{1}$ (a) Michon, C.; Abadie, M.-A. Medina, F.; Agbossou-Niedercorn, F. Recent metal-catalysed asymmetric hydroaminations of alkenes. $J$. Organomet. Chem. 2017, 847, 13-27; (b) Lepori, C.; Hannedouche, J. First-Row Late Transition Metals for Catalytic (Formal) Hydro-amination of Unactivated Alkenes. Synthesis 2017, 49, 11581167; (c) Huang, L.; Arndt, M.; Gooßen, K.; Heydt, H.; Gooßen, L. J. Late Transition Metal-Catalyzed Hydroamination and Hydroamidation. Chem. Rev. 2015, 115, 2596-2697; (d) Bernoud, E.; Lepori, C.; Mellah, M.; Schulz, E.; Hannedouche, J. Recent advances in metal free- and late transition metal-catalysed hydroamination of unactivated alkenes. Catal. Sci. Technol. 2015, 5, 2017-2037; (e) Rodriguez-Ruiz, V.; Carlino, R.; Bezzenine-Lafollée, S.; Gil, R.; Prim, D.; Schulz E.; J. Hannedouche. Recent developments in alkene hydro-functionalisation promoted by homogeneous catalysts based on earth abundant elements: formation of $\mathrm{C}-\mathrm{N}, \mathrm{C}-\mathrm{O}$ and $\mathrm{C}-\mathrm{P}$ bond. Dalton Trans. 2015, 44, 12029-12059; (f) Hannedouche J.; Schulz, E. Asymmetric Hydroamination: A Survey of the Most Recent Developments. Chem. Eur. J. 2013, 19, 4972-4985; (g) Hesp K. D.; Stradiotto, M. Rhodium- and Iridium-Catalyzed Hydroamination of Alkenes. ChemCatChem 2010, 2, 1192-1207; (h) Muller, T. E.; Hultzsch, K. C.; Yus, M.; Foubelo F.; Tada, M. Hydroamination: Direct Addition of Amines to Alkenes and Alkynes. Chem. Rev. 2008, 108, 3795-3892.

2 (a) Roesky, P. W. Catalytic Hydroaminoalkylation. Angew. Chem. Int. Ed. 2009, 48, 4892-4894; (b) Chong, E.; Garcia, P. Schafer, L. Hydroaminoalkylation: early-transition-metal-catalyzed $\alpha$ alkylation of amines. Synthesis 2014, 46, 2884-2896.

(a) Gribkov, D. V.; Hultzsch, K. C.; Hampel, F. 3,3'Bis(trisarylsilyl)-substituted binaphtholate rare earth metal catalysts for asymmetric hydroamination J. Am. Chem. Soc. 2006, 128, $3748-$ 3759; (b) Reznichenko, A. L.; Nguyen, H. N.; Hultzsch, K. C.
Asymmetric intermolecular hydroamination of unactivated alkenes with simple amines. Angew. Chem., Int. Ed. 2010, 49, 8984-8987.

${ }^{4}$ Manna, K.; Kruse, M. L.; Sadow, A. D. Concerted CN/CH bond formation in highly enantioselective Yttrium(III)-catalyzed hydroamination. ACS Catal. 2011, 1, 1637-1642.

${ }^{5}$ Reznichenko, A. L.; Hultzsch, K. C. $C_{1}$-Symmetric rare-earthmetal aminodiolate complexes for intra- and intermolecular asymmetric hydroamination of alkenes. Organometallics 2013, 32, 1394-1408.

6 (a) Huynh, K.; Livinghouse, T.; Lovick, H. M. $N, N^{\prime}-$ Dibenzosuberyl-1,1'-binaphthyl-2,2'-diamine: a highly effective supporting ligand for the enantioselective cyclization of aminoalkenes catalyzed by chelating diamide complexes of $\mathrm{La}(\mathrm{III})$ and $\mathrm{Y}(\mathrm{III})$. Synlett 2014, 25, 1721-1724. (b) Huynh, K.; Anderson, B. K.; Livinghouse, T. Enantioselective hydroamination/cyclization of aminoalkenes by (bis)- $C_{2}$ symmetric and (mono)- $C_{2}$ symmetric anionic tetraamide complexes of La(III). Tetrahedron Lett. 2015, 56, 3658 3661.

7 Bennett, S. D.; Core, B. A.; Blake, M. P.; Pope, S. J. A.; Mountford, P.; Ward, B. D. Chiral lanthanide complexes: coordination chemistry, spectroscopy, and catalysis. Dalton Trans. 2014, 43, 5871-5885.

${ }^{8}$ Chai, Z.; Hua, D.; Chu, K. Li, J.; Yang, G. A novel chiral yttrium complex with a tridentate linked amido-indenyl ligand for intramolecular hydroamination. Chem.Commun. 2014, 50, 177-179.

${ }^{9}$ Song, G.; W. N. O, W.; Hou, Z. Enantioselective C-H Bond Addition of Pyridines to Alkenes Catalyzed by Chiral Half-Sandwich Rare-Earth Complexes. J. Am. Chem. Soc. 2014, 136, 12209-12212.

${ }^{10}$ Teng, H.-L.; Luo, Y.; Wang, B.; Zhang, L.; M. Nishiura, Hou, Z. Synthesis of chiral aminocyclopropanes by rare-earth-metal-catalyzed cyclopropene hydroamination. Angew. Chem. Int. Ed. 2016, 55, 15406-15410.

${ }^{11}$ Teng, H.-L; Ma, Y.; Zhan, G.; Nishiur, M.; Hou, Z. Asymmetric $\mathrm{C}(\mathrm{sp})-\mathrm{H}$ addition of terminal alkynes to cyclopropenes by a chiral gadolinium catalyst. ACS Catal. 2018, 8, 4705-4709.

${ }^{12}$ For initial reports: (a) Manna, K.; Xu, S.; Sadow, A. D. A Highly enantioselective zirconium catalyst for intramolecular alkene hydroamination: significant isotope effects on rate ands. Angew. Chem. Int. Ed. 2011, 50, 1865 - 1868; (b) reference 4.

${ }^{13}$ Manna, K.; Everett, W. C.; Schoendorff, G.; Ellern, A.; Windus, T. L.; Sadow, A. D. Highly enantioselective zirconium-catalyzed cyclization of aminoalkenes. J. Am. Chem. Soc. 2013, 135, $7235-7250$.

${ }^{14}$ Manna, K.; Eedugurala, N.; Sadow, A. D. Zirconium-Catalyzed Desymmetrization of Aminodialkenes and Aminodialkynes through Enantioselective Hydroamination. J. Am. Chem. Soc. 2015, 137, 425435.

${ }^{15}$ Biyikal, M.; Löhnwitz, K.; Roesky, P. W.; Blechert, S. Preparation and Catalytic Performance of Novel Dimeric Tetranuclear Zinc Complexes in Hydroamination of Alkenes at Room Temperature. Synlett 2008, 20, 3106-3110.

${ }^{16}$ Hussein, L.; Purkait, N.; Biyikal, M.; Tausch, E. Roesky, P. W.; Blechert, S. Highly enantioselective hydroamination to six-membered rings by heterobimetallic catalysts. Chem.Commun. 2014, 50, 38623864.

${ }^{17}$ Zhou, X.; Wei, B.;. Sun, X.-L; Tang, Y.; Xie, Z. Asymmetric hydroamination catalyzed by a new chiral zirconium system: reaction scope and mechanism. Chem. Commun. 2015, 51, 5751-5753.

8 Braun, C.; Bräse, S.; Schafer, L. L. Planar-Chiral [2.2]Paracyclophane-Based Amides as Proligands for Titanium- and Zirconium-Catalyzed Hydroamination. Eur. J. Org. Chem. 2017, $1760-1764$.

${ }^{19}$ Hansen, M. C.; Heusser, C. A.; Narayan, T. C.; Fong, K. E.; Hara, N.; Kohn,A. W.; Venning, A. R.; Rheingold, A. L; Johnson A. R. Asymmetric Catalytic Intramolecular Hydroamination of Aminoallenes by Tantalum Amidoalkoxide Complexes. Organometallics 2011, 30, 4616-4623. 
${ }^{20}$ Zhang, F.; Song, H.; Zi, G. Synthesis and catalytic activity of group 5 metal amides with chiral biaryldiamine-based ligands. Dalton Trans. 2011, 40, 1547-1566.

${ }^{21}$ Reznichenko, A. L.; Emge, T. J.; Audörsch, S.; Klauber, E. G.; Kultzsch, K. C.; Schmidt, B. Group 5 Metal Binaphtholate Complexes for Catalytic Asymmetric Hydroaminoalkylation and Hydroamination/Cyclization Organometallics 2011, 30, 921-924.

22 (a) Abadie, M.-A.; Trivelli, X.; Medina, F.; Capet, F.; Roussel, Agbossou-Niedercorn, F.; Michon, C. Asymmetric Intramolecular Hydroamination of Alkenes in Mild and Wet Conditions-Structure and Reactivity of Cationic Binuclear Gold(I) Catalysts. ChemCatChem 2014, 6, 2235-2239; (b) Abadie, M.-A.; Trivelli, X.; Medina, F.; Duhal, N.; Kouach, M.; Linden, B.; Génin, E.; Vandewalle, M.; Capet, F.; Roussel, P.; Del Rosal, I; Maron, L; Agbossou-Niedercorn, F.; Michon, C. Gold(I)-Catalysed Asymmetric Hydroamination of Alkenes: A Silver- and Solvent-Dependent Enantiodivergent Reaction. Chem. Eur. J. 2017, 23, 10777-10788; (c) Yu, F.; Chen, P.; Liu, G. Pd(II)-catalyzed intermolecular enantioselective hydroamination of styrenes. Org. Chem. Front. 2015, 2, 819-822; (d) Gao, P.; Sipos, G.; Foster, D.; Dorta R. Developing NHC-Iridium Catalysts for the Highly Efficient Enantioselective Intramolecular Hydroamination Reaction. ACS Catal. 2017, 7, 60606064.

${ }^{23}$ (a) Miki, Y.; Hirano, K.; Satoh, T.; Miura, M. Copper-Catalyzed Intermolecular Regioselective Hydroamination of Styrenes with Polymethylhydrosiloxane and Hydroxylamines. Angew. Chem. Int. Ed. 2013, 52, 10830-10834. (b) Zhu, S.; Niljianskul, N.; Buchwald, S. L. Enantio- and Regioselective $\mathrm{CuH}-$ Catalyzed Hydroamination of Alkenes. J. Am. Chem. Soc. 2013, 135, 15746-15749.

${ }^{24}$ For a review and historical background: Pirnot, M. T.; Wang, Y.M.; Buchwald, S. L. Copper Hydride Catalyzed Hydroamination of Alkenes and Alkynes. Angew. Chem., Int. Ed. 2016, 55, 48-57.

${ }^{25}$ (a) Zhu, S.; Buchwald, S. L. Enantioselective CuH-Catalyzed Anti-Markovnikov Hydroamination of 1,1-Disubstituted Alkenes $J$. Am. Chem. Soc. 2014, 136, 15913-15916. (b) Yang, Y.; Shi, S.-L.; Niu, D.; Liu, P.; Buchwald, S. L. Catalytic asymmetric hydroamination of unactivated internal olefins to aliphatic amines. Science (Washington, D. C.) 2015, 349, 62-66. (c) Xi, Y.; Butcher, T. W.; Zhang, J.; Hartwig, J. F. Regioselective, Asymmetric Formal Hydroamination of Unactivated Internal Alkenes. Angew. Chem. Int. Ed. 2016, 55, 776-780. (d) Niljianskul, N.; Zhu, S.; Buchwald, S. L. Enantioselective Synthesis of a-Aminosilanes by Copper-Catalyzed Hydroamination of Vinylsilanes. Angew. Chem. Int. Ed. 2015, 54, 1638-1641; (e) Nishikawa, D.; Hirano, K.; Miura M. Asymmetric Synthesis of $\alpha$-Aminoboronic Acid Derivatives by Copper-Catalyzed Enantioselective Hydroamination J. Am. Chem. Soc. 2015, 137, 15620-15623. (f) Niu, D.; Buchwald, S. L. Design of Modified Amine Transfer Reagents Allows the Synthesis of $\alpha$-Chiral Secondary Amines via CuH-Catalyzed Hydroamination. J. Am. Chem. Soc. 2015, 137, 9716-9721. (g) Bandar, J.; Pirnot, M. T., Buchwald, S. L. Mechanistic Studies Lead to Dramatically Improved Reaction Conditions for the Cu-Catalyzed Asymmetric Hydroamination of Olefins. J. Am. Chem. Soc. 2015, 137, 14812-14818; (h) Lu, G.; Liu, R. Y.; Yang, Y.; Fang, C.; Lambrecht, D. S.; Buchwald, S. L.; P. Liu. Ligand-Substrate Dispersion Facilitates the Copper-Catalyzed Hydroamination of Unactivated Olefins. J. Am. Chem. Soc. 2017, 139, 16548-16555. (i) Wang, H.; Yang, J. C.; Buchwald S. L. CuHCatalyzed Regioselective Intramolecular Hydroamination for the Synthesis of Alkyl-Substituted Chiral Aziridines. J. Am. Chem. Soc. 2017, 139, 8428-8431. (j) Ichikawa, S.; Zhu, S.; Buchwald S. L. A Modified System for the Synthesis of Enantioenriched N-Arylamines through Copper-Catalyzed Hydroamination. Angew. Chem. Int. Ed. 2018, $57,8714-8718$.

${ }^{26}$ (a) Shi, S.-L.; Buchwald, S. L. Copper-catalysed selective hydroamination reactions of alkynes. Nat. Chem. 2015, 7, 38-44. (b) Zhu, S.;Niljianskul, N.; Buchwald, S. L. A direct approach to amines with remote stereocentres by enantioselective $\mathrm{CuH}$-catalysed reductive relay hydroamination. Nat. Chem. 2016, 8, 144-150. (c) Shi, S.L.; Wong, Z. L.; Buchwald, S. L. Copper-catalysed enantioselective stereodivergent synthesis of amino alcohols. Nature (London) 2016, 532, 353-356.

27 Tobisch, S. CuH-catalysed hydroamination of styrene with hydroxylamine esters: A coupled cluster scrutiny of mechanistic pathways. Chem. Eur. J. 2016, 22, 8290-8300.

${ }^{28}$ Clerici, M. G.; Maspero, F. Catalytic C-alkylation of secondary amines with alkenes. Synthesis 1980, 305-306.

${ }^{29}$ Nugent, W. A.; Ovenall, D. W.; Holmes, S. J. Catalytic C-H activation in early transition-metal dialkylamides and alkoxides. Organometallics 1983, 2, 161-162.

${ }^{30}$ (a) Boerner, A.; Beller, M.; Wuensch, B. Synthesis of lakyl- and cycloalkylamines by hydroaminomethylation of alkenes. Science of Syntheses, 2009, 40a, 111-117; (b) Chen, C.; Dong, X.-Q.; Zhang, X. Recent progress in rhodium-catalyzed hydroaminomethylation. Org. Chem. Front. 2016, 3, 1359-1370; (c) Kalck, P.; Urrutigoity, M.

Tandem Hydroaminomethylation reaction to synthesize amines froma alkenes. Chem. Rev. 2018, 118, 3833-3861.

31 Herzon, S. B.; Hartwig, J. F. Direct, Catalytic Hydroaminoalkylation of Unactivated Olefins with N-Alkyl Arylamines. J. Am. Chem. Soc. 2007, 129, 6690-6691.

32 Herzon, S. B.; Hartwig, J. F. Hydroaminoalkylation of Unactivated Olefins with Dialkylamines J. Am. Chem. Soc. 2008, 130, 14940-14941.

${ }^{33}$ Eisenberger, P.; Ayinla, R. O.; PLauzon, J. M. P.; Schafer, L. L. Tantalum-amidate complexes for the hydroaminoalkylation of secondary amines: enhanced substrate scope and enantioselective chiral amine synthesis. Angew. Chem. Int. Ed. 2009, 48, 8361-8365.

34 Zi, G.; Zhang, F.; Song, H. Highly enantioselective hydroaminoalkylation of secondary amines catalyzed by group 5 metal amides with chiral biarylamidate ligands. Chem. Commun. 2010, 46, 6296-6298.

${ }^{35}$ Zhang, F.; Song, H.; Zi, G. Synthesis and catalytic activity of group 5 metal amides with chiral biaryldiamine-based ligands. Dalton Trans. 2011, 40, 1547-1566.

36 Reznichenko, A. L.; Hultzsch, K. C. The mechanism of hydroaminoalkylation catalyzed by group 5 metal binaphtholate complexes. J. Am. Chem. Soc. 2012, 134, 3300-3311.

${ }^{37}$ Hameaoui, B.; Pelletier, J. D. A.; Abou-Hamad, E.; Chen, Y.; El Eter, M.; Chermak, E.; Cavallo, L.; Basset, J.-M. Solid-state NMR and DFT studies on the formation of well-defined silica-supported tantallaaziridines: from synthesis to catalytic application. Chem. Eur. J. 2016, 22, 3000-3008.

${ }^{38}$ Zhang, Z.; Hamel, J.-D.; Schafer, L. L. TaMe $\mathrm{Cl}_{2}$-catalyzed intermolecular hydroaminoalkylation: a simple complex for enhanced reactivity and expanded substrate scope. Chem. Eur. J. 2013, 19, 8751-8754.

${ }^{39}$ Garcia, P.; Payne, P. R.; Chong, E.; Webster, R. L.; Barron, B. J.; Behrle, A. C.; Schmidt, J. A. R.; Schafer, L. L. Easily assembled, modular $N, O$-chelating ligands for $\mathrm{Ta}(\mathrm{V})$ complexation: a comparative study of ligand effects in hydroaminoalkylation with $\mathrm{N}$ methylaniline and 4-methoxy- $N$-methylaniline. Tetrahedron, 2013, $69,5737-5743$.

${ }^{40}$ Lauzon, J. M.; Eisenberger, P.; Roşca, S.-C.; Schafer, L. L. Amidate complexes of tantalum and niobium for the hydroaminoalkylation of unactivated alkenes. ACS Catal. 2017, 7, 5921-5931.

${ }^{41}$ Payne, P. R.; Garcia, P.; Eisenberger, P.; Yim, J. C.-H.; Schafer, L. L. Tantalum catalyzed hydroaminoalkylation for the synthesis of $\alpha$ and $\beta$-substituted $N$-heterocycles. Org. Lett. 2013, 15, 2182-2185.

42 Garcia, P.; Lau, Y. Y.; Perry, M. R.; Schafer, L. L. Phosphoramidate tantalum complexes for room-temperature $\mathrm{C}-\mathrm{H}$ functionalization: hydroaminoalkylationc. Angew. Chem. Int. Ed. 2013, 52, 9144-9148.

${ }^{43}$ Chong, E.; Brandt, J. W., Schafer, L. L. 2-Pyridonate tantalum complexes for the intermolecular hydroaminoalkylation of sterically demanding alkenes. J. Am. Chem. Soc. 2014, 136, 10898-10901.

${ }^{44}$ Brandt, J. W., Chong, E.; Schafer, L. L. Ligand effects and kinetic investigations of sterically accessible 2-pyridonate tantalum 
complexes for Hydroaminoalkylation. ACS Catal. 2017, 7, 63236330.

${ }^{45}$ Edwards, P. M.; Schafer, L. L. In Situ generation of a regio- and diastereoselective hydroaminoalkylation catalyst using commercially available starting materials. Org. Lett. 2017, 19, 5720-5723.

${ }^{46}$ DiPucchio, R.; Roșca, S.-C.; Schafer, L. L. Catalytic and atom economic Csp3 - Csp3 bond formation $\alpha$-to nitrogen. alkyl tantalum ureates for hydroaminoalkylation. Angew. Chem. Int. Ed. 2018, 57, 3469-3472.

47 Kubiak, R.; Prochnow, I.; Doye, S. Titanium-Catalyzed Hydroaminoalkylation of Alkenes by $\mathrm{C}-\mathrm{H}$ Bond Activation at $\mathrm{sp}^{3}$ Centers in the $\alpha$-Position to a Nitrogen Atom. Angew. Chem. Int. Ed. 2009, 48, 1153-1156.

${ }^{48}$ Kubiak, R.; Prochnow, I.; Doye, S. [ $\left.\operatorname{Ind}_{2} \mathrm{TiMe}_{2}\right]$ : a catalyst for the hydroaminomethylation of alkenes and styrenes. Angew. Chem. Int. Ed. 2010, 49, 2626-2629.

49 Ryken, S. A.; Schafer, L. A. N,O-chelating four-membered metallacyclic titanium(IV) complexes for atom-economic catalytic reactions. Acc. Chem. Res. 2015, 48, 2576-2586.

${ }^{50}$ Chong, E.; Schafer, L. L. 2-Pyridonate titanium complexes for chemoselectivity. Accessing intramolecular hydroaminoalkylation over hydroamination. Org. Lett. 2013, 15, 6002-6005.

${ }^{51}$ Bexrud, J. A.; Eisenberger, P.; Leitch, D. C.; Payne, P. R.; Schafer, L. L. Selective C-H activation $\alpha$ to primary amines. Bridging metallaaziridines for catalytic, intramolecular $\alpha$-alkylation. J. Am. Chem. Soc. 2009, 131, 2116-2118.

${ }^{52}$ Manßen, M.; Lauterbaxh, N.; Dörfler, J.; Schmidtmann, M.; Saak, W.; Doye, S.; Beckaus, R. Efficient access to titanaaziridines by $\mathrm{C}-\mathrm{H}$ activation of $\mathrm{N}$-methylanilines at ambient temperature. Angew. Chem. Int. Ed. 2015, 54, 4383-4387.

${ }^{53}$ El Eter, M.; Hamzaoui, B.; Abou-Hamad, E.; Pelletier, J. D. A.; Basset, J.-M. Well-defined azazirconacyclopropane complexes supported on silica structurally determined by 2D NMR comparative elucidation. Chem. Commun. 2013, 49, 4616-4618.

${ }^{54}$ Hamzaoui, B.; Pelletier, J. D. A.; El Eter, M.; Chen, Y.; AbouHamad, E.; Basset, J.-M. Isolation and characterization of welldefined silica-supported azametallacyclopentane: a key intermediaite in catlytic hydroaminoalkylation reactions. Adv. Synth. Catal. 2015, 357, 3148-3154.

${ }^{55}$ Dörfler, J.; Bytyqi, B.; Hüller, S.; Mann, N. M.; Brahms, C.; Schmidtmann, M.; Doye, S. An aminopyridinato titanium catalyst for the intramolecular hydroaminoalkylation of secondary aminoalkenes. Adv. Synth. Catal. 2015, 357, 2265-2276.

${ }^{56}$ Dörfler, J.; Preu $\beta$, T.; Schischko, A.; Schmidtmann, M.; Doye, S. A 2,6-bis(phenylamino)pyridinato titanium catalyst for the highly regioselective hydroaminoalkylation of styrenes and 1,3-butadienes. Angew. Chem. Int. Ed. 2014, 53, 7918-7922.
${ }^{57}$ Dörfler, J.; Preu $\beta$, T.; Brahms, C.; Scheuer, D.; Doye, S. Intermolecular hydroaminoalkylation of alkenes and dienes using a titanium mono(formamidinate) catalyst. Dalton Trans. 2015, 44, 1214912168.

${ }^{58}$ Weers, M.; Lühning, L. H.; Lührs, V.; Brahms, C.; Doye, S. One-pot procedure for the synthesis of 1,5-benzodiazepines from $\mathrm{N}$ allyl-2-bromoanilines. Chem. Eur. J. 2017, 23, 1237-1240.

59 Lühning, L. H.; Strehl, J.; Schmidtmann, M.; Doye, S. Hydroaminoalkylation of allylsilanes and a one-pot procedure for the synthesis of 1,5-benzoazasilepines. Chem. Eur. J. 2017, 23, $4197-$ 4202.

${ }^{60}$ Lühning, L. H.; Rosien, M.; Doye, S. Titanium-catalyzed hydroaminoalkylation of vinylsilanes and a one-pot procedure for the synthesis of 1,4-benzoazasilines. Synlett 2017, 28, 2489-2494.

61 Bielefeld, J.; Doye, S. Dimethylamine as a substrate in hydroaminoalkylation reactions. Angew. Chem. Int. Ed. 2017, 56, 15155-15158.

${ }^{62}$ Nako, A; E. Oyamada, J.; Nishiuura, M.; Hou, Z. Scandiumcatalysed intermolecular hydroaminoalkylation of olefins with aliphatic tertiary amines. Chem. Sci. 2016, 7, 6429-6434.

${ }^{63}$ Liu, F.; Luo, G.; Hou, Z.; Luo, Y. Mechanistic insights into scandium-catalyzed hydroaminoalkylation of olefins with amines: origin of regioselectivity and charge-based prediction model. Organometallics 2017, 36, 1557-1565.

${ }^{64}$ Gao, H.; Su, J.; Xu, P.; Xu, X. Scandium-catalyzed C( $\left.\mathrm{sp}^{3}\right)-\mathrm{H}$ alkylation of $N, N$-dimethyl anilines with alkenes. Org. Chem. Front. 2018, 5, 59-63.

${ }^{65}$ Newton, C. G.; Wang, S.-G.; Oliveira, C. C.; Cramer, N. Catalytic enantioselective transformations involving $\mathrm{C}-\mathrm{H}$ bond cleavage by transition-metal complexes. Chem. Rev. 2017, 117, 8908-8976.

${ }^{66} \mathrm{Li}, \mathrm{Q}$.; Yu, Z.-X. Enantioselective rhodium-catalyzed allylic C-H activation for the addition to conjugated dienes. Angew. Chem. Int Ed. 2011, 50, 2144-2147.

${ }^{67}$ Pan, S.; Endo, K.; Shibata, T. Ir(I)-catalyzed enantioselective secondary $\mathrm{sp}^{3} \mathrm{C}-\mathrm{H}$ bond activation of 2-(alkylamino)pyridines with alkenes. Org. Lett. 2011, 13, 4692-4695.

${ }^{68}$ Pan, S.; Matsuo, Y.; Endo, K.; Shibata, T. Cationic iridiumcatalyzed enantioselective activation of secondary $\mathrm{sp}^{3} \mathrm{C}-\mathrm{H}$ bond adjacent to nitrogen atom. Tetrahedron, 2012, 68, 9009-9015

${ }^{69}$ Tahara, Y.-k.; Michino, M.; Ito, M.; Kanyiva, K. S.; Shibata, T. Enantioselective $\mathrm{sp}^{3} \mathrm{C}-\mathrm{H}$ alkylation of $\gamma$-butyrolactam by a chiral $\operatorname{Ir}(\mathrm{I})$ catalyst for the synthesis of 4 -substituted $\gamma$-amino acids. Chem. Commun. 2015, 51, 16660-16663.

70 Torigoe, T.; Ohmura, T.; Suginome, M. Asymmetric cycloisomerization of $o$-alkenyl- $N$-methylanilines to indolines by iridium-catalyzed $\mathrm{C}\left(\mathrm{sp}^{3}\right)-\mathrm{H}$ addition to carbon-carbon double bonds. Angew. Chem. Int. Ed. 2017, 56, 14272-14276.

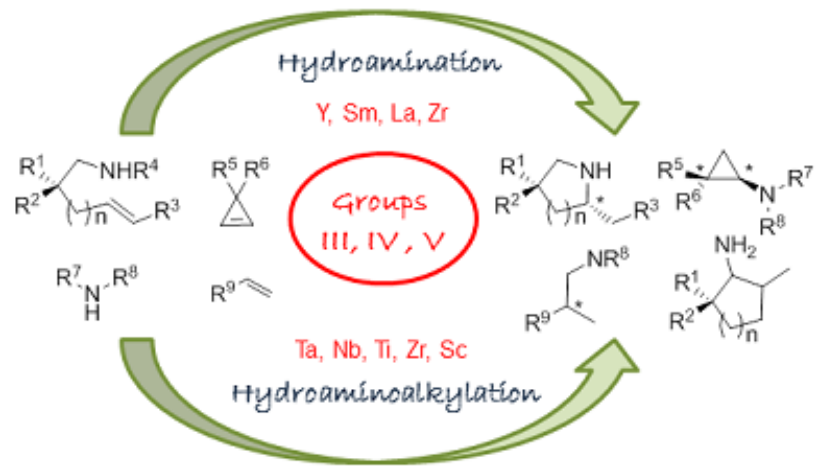

